\title{
Gender disparities in perceived life satisfaction within food insecure populations
}

Elizabeth A. Graham

School of Dietetics and Human Nutrition

McGill University, Montreal, Canada

2015

A thesis submitted to McGill University in partial fulfillment of the requirements of the degree of Master of Science

(C) Elizabeth A. Graham 2015 


\section{Abstract}

Food insecurity plagues individuals worldwide, even in those countries with a surplus in food supplies. Numerous studies show females are over-represented among the global food insecure population; a 2009 estimate reported $60 \%$ of undernourished people worldwide are women or girls. Little research has examined the way food insecure affects men and women's perception of their own life satisfaction. By asking individuals whether they are satisfied with their lives, underlying crises or hidden strengths can be understood. The primary objective of this study is to analyse whether gender is a global risk factor for experiencing food insecurity. The secondary objective is to explore the relationship between food insecurity and reported life satisfaction, and how that relationship may be more pronounced by gender. Through a collaboration with the Food and Agriculture Organization of the UN, this study utilized data collected through the 2014 Gallup World Poll ${ }^{\circledR}$ (GWP) which included the Food Insecurity Experience Scale (FIES). The GWP is a nationally representative survey conducted annually in over 150 countries. Responses to the FIES ( 8 questions) comprised the food insecurity variable, with 0 affirmative responses denoting food security, and 1-8 affirmative responses denoting food insecurity. A single wellbeing question (adapted from Hadley Cantril's Self-Anchoring Striving Scale) comprised the life satisfaction variable, with possible answers ranged 0-10. Responses 4 or lower denoted "worse off" or low life satisfaction, versus 5-10 categorized "better off". Analysis was conducted using IBM SPSS Statistics 22, using the complex sample module. Descriptive and bivariate analyses were employed to understand which independent variables are related to life satisfaction, considering intensity and direction. Two multivariate logistic regression models were created; one to examine the likelihood of being food insecure based on gender, and another to examine the likelihood of reporting higher life satisfaction based on food security status and gender. Both models adjusted for age, marital status, income, education level, and country of residence. Cross-sectional data from 142 countries shows that, globally, $47.7 \%$ of population was food insecure, with nearly a third of the total sample (32.4\%) categorized as "worse off" for life satisfaction. Women had higher odds for food insecurity than men in both unadjusted (OR: 1.14, 95\% Cl=1.11-1.16), as well as adjusted models (OR: 1.04, 95\% Cl=1.01-1.07). Food insecurity and life satisfaction were found significantly correlated, with those who were food insecure having significantly higher odds of perceiving low life satisfaction (OR: $3.25,95 \% \mathrm{Cl}=$ 3.14-3.36). Furthermore, this analysis revealed for the first time on a global scale, that men are consistently less likely to report higher life satisfaction than their female counterparts (OR: $0.83,95 \% \mathrm{Cl}=0.81-0.86)$ when controlling for food insecurity, among other variables. Adjusting for independent variables, food insecure men, food insecure women, and food secure men had, respectively, 3.89, 3.31, and 1.24 times higher odds to report "worse off" life satisfaction when compared to food secure women. This research provides evidence of differing reports of overall life satisfaction between men and women who experience the same food (in)security status. This reinforces the need for re-structuring typical food-security programs (and other public services) and to measure individual well-being consequences which often precede physical consequences of food insecurity. This study supports implementing well-being and food insecurity assessments in unison, to understand how food insecurity in specific economic and social contexts varies. Continued research is necessary to explore why life satisfaction is viewed differently by men and women, what the consequences are then for those food insecure populations and what implications exist for policies aimed at improving food security. 


\section{Résumé}

L'insécurité alimentaire est un problème qui affecte plusieurs individus sur l'échelle mondiale, même dans certains pays où la nourriture est abondante. Parmi ceux qui sont affectés, les hommes et les femmes sont sujets à de différentes expériences d'insécurité alimentaire. En ce qui concerne la population mondiale sujette à l'insécurité alimentaire, de nombreuses études démontrent que les femmes sont affectées davantage que les hommes. En 2009, il était estimé que $60 \%$ des personnes sous-alimentées dans le monde étaient des femmes ou des filles. Peu d'études existent qui cherchent à évaluer la manière dont les personnes atteintes d'insécurité alimentaire perçoivent leur satisfaction de vie, et si celle-ci diffère selon le sexe. Une telle satisfaction est souvent utilisée comme un indicateur subjectif du bienêtre. En demandant aux personnes si elles sont satisfaites avec leur vie, des informations importantes peuvent être acquises sur le bienêtre de la société. Ces informations peuvent permettre la découverte de problèmes et de forces au sein de la société. L'objectif principal de cette étude est d'analyser si le sexe est un facteur de risque pour l'insécurité alimentaire, sur une échelle mondiale. Le deuxième objectif de cette étude est d'explorer la relation entre l'insécurité alimentaire et la satisfaction de vie, et si cette relation peut être amplifier par le sexe des individus. En collaboration avec l'Organisation des Nations Unies pour l'alimentation et l'agriculture, cette étude a utilisé les données recueillies par le Gallup World Poll ${ }^{\circledR}$ 2014, un questionnaire qui comporte l'échelle d'expérience d'insécurité alimentaire (FIES). Le GWP est un questionnaire qui est administré chaque année dans plus de 150 pays, parmi des échantillons représentatifs. Les réponses aux FIES (8 questions) représentent la variable de l'insécurité alimentaire, et les réponses à une question sur le bienêtre dans le GWP (adapté de l'échelle Hadley Cantril's SelfAnchoring Striving Scale) représente la variable de la satisfaction de vie. L'analyse statistique a été réalisée à l'aide du logiciel IBM SPSS Statistics 22, en utilisant le module intitulé Complex Samples. Des analyses statistiques descriptives et bivariées ont été utilisées afin de comprendre quelles variables (âge, sexe, état matrimonial, le revenu, l'éducation, et l'insécurité alimentaire) sont liées à la satisfaction de vie, et comment elles interagissent. Deux modèles de régression logistique multivariée ont été utilisés; un pour examiner la probabilité d'être sujet à l'insécurité alimentaire par rapport au sexe, et un autre pour examiner la probabilité de déclarer une satisfaction de vie élevée par rapport au statu de sécurité alimentaire et le sexe. Les deux modèles ont été ajustés pour l'âge, le statu de mariage, le revenu, le niveau d'éducation, et le pays de résidence. Les résultats des données transversales de 142 pays démontrent que 47,7\% des répondants subissent de l'insécurité alimentaire. Plus précisément, un tiers de l'échantillon $(32,4 \%)$ classifiés avec une insécurité alimentaire "sévère". Les femmes étaient beaucoup plus susceptibles d'être atteintes d'insécurité alimentaire que les hommes sans ajustement des variables (OR: 1,14, IC à 95\% = 01.11 à 01.16), et avec ajustements des variables (OR: 1,04, IC à $95 \%=1.1$ à 1.7). De plus, l'insécurité alimentaire et la satisfaction de vie démontrent une corrélation significative. Plus précisément, les sujets atteints d'insécurité alimentaire sont plus à risque d'avoir une faible satisfaction de vie (OR: 3,25, IC à $95 \%=3,14$ à 3,36). De plus, d'autres analyses ont démontrées, pour la première fois sur l'échelle mondiale, que les femmes sont plus prônes à déclarer qu'elles sont satisfaites avec leurs vies que les hommes (OR: 0,83, IC à $95 \%=0,81$ à 0,86 ), lorsque la variable d'insécurité alimentaire, et autres, étaient contrôlées. Cette recherche fournit des preuves que les perceptions de satisfaction de vie varient entre les hommes et les femmes subissant le même niveau d'insécurité alimentaire. Ceci met emphase 
sur le besoin de restructurer les programmes typiques qui adressent l'insécurité alimentaire (et d'autres services publics) afin qu'ils mesurent le bienêtre des individus, avant que les conséquences physiques de l'insécurité alimentaire prennent place. Cette étude supporte la mise en place d'évaluation de bienêtre en addition aux questionnaires de sécurité alimentaire, et vice versa, pour pouvoir évaluer l'impact des contextes économiques et sociaux sur l'insécurité alimentaire. Il est nécessaire de continuer la recherche, concernant la satisfaction de vie, pour explorer les différentes perceptions entres les hommes et les femmes et l'impact que ceci pourrait avoir sur les politiques de sécurité alimentaire. 


\section{Acknowledgements}

I conclude this research with incredible gratitude for the generous individuals I have worked with. I thank my primary supervisor, Dr. Hugo Melgar-Quiñonez, for inspiring me to think critically and compassionately in research. Dr. Melgar-Quiñonez will often tell his students that a worried mind is inevitable when working to combat global food insecurity, but through his example I've seen that sustenance follows, too.

Terri Ballard, my co-supervisor and mentor, was instrumental from conceptualization through final edits. I am grateful for her patience and precise leadership, and in showing me la dolce vita in Roma's urban and household kitchens. Thanks to Diana Dallmann, for her immense statistical support, attention to detail, and thoughtful presence in conceptualizing this analysis.

I am indebted to the Voices of the Hungry team members at FAO, who provided an energizing environment in which to explore this research. In particular, thanks to teammates Mauro del Grossi and Sara Viviani who offered statistical mentorship and their quantitative research expertise, always with warm encouragement. Meghan Miller was a special confidant and collaborator throughout this work. To the VoH team leader, Carlo Cafiero, I am grateful for his trust in my work and his Neapolitan manner. He is a true teacher.

Thank you to the School of Dietetics and Human Nutrition at McGill University, as well as the Food Security Research Group at Macdonald Campus, a unique space of collaboration and contemplation. I am a better researcher for these and many other shares of support. 


\section{Contribution of Authors}

The manuscript included in this thesis was accomplished through collaboration with each of the co-authors. As the first author of the manuscript, I was responsible for the conceptualization of the research questions, data analysis, interpretation of results, and for writing the article. Dr. Hugo Melgar-Quiñonez and Terri Ballard provided guidance and supervision through all stages of the research project, including conceptualizing the analysis and interpreting the results. Diana Dallmann provided data cleaning, refining the regression models, and extensive statistical support throughout the research project. Gabrielle Helal provided French translation support. The Voices of the Hungry team at the Food and Agriculture Organization of the United Nations was responsible for the conceptualization of the Food Insecurity Experience Scale, as well as methodological support in the analysis. The Voices of the Hungry team included Mark Nord, Terri Ballard, Anne Kepple, Carlo Cafiero, Sara Viviani, Verena Wilke, Mauro DelGrossi, Aymeric Songy, and Meghan Miller. Gallup World Poll administered data collection and delivery. 
Table of Contents

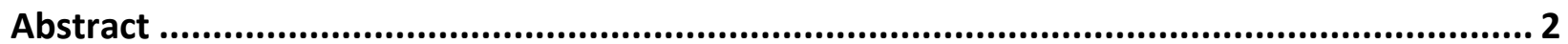

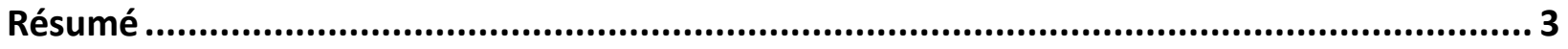

Acknowledgements .............................................................................................. 5

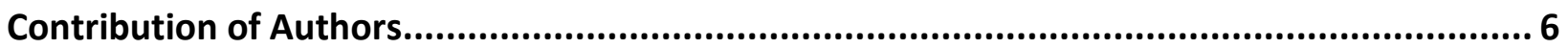

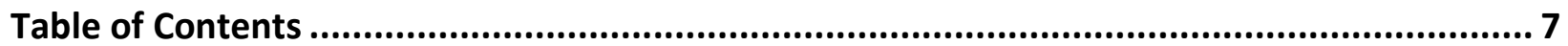

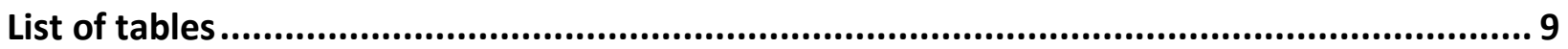

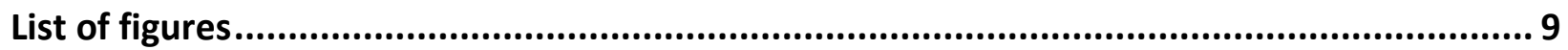

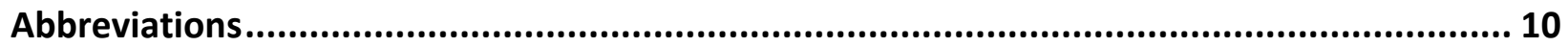

Chapter 1: General overview ............................................................................... 11

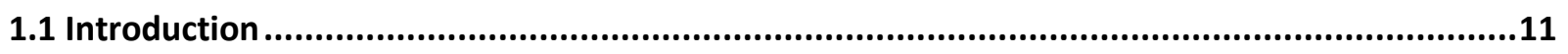

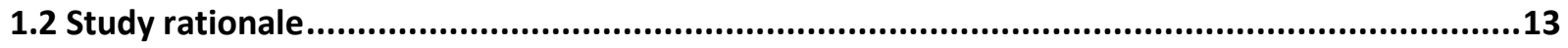

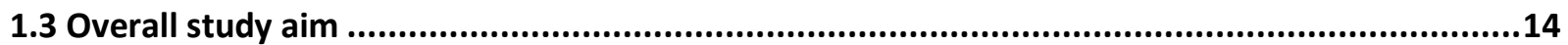

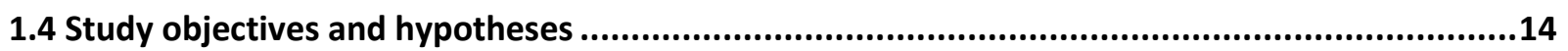

Chapter 2: Literature review .................................................................................... 15

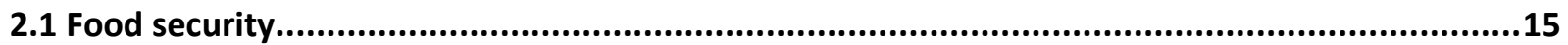

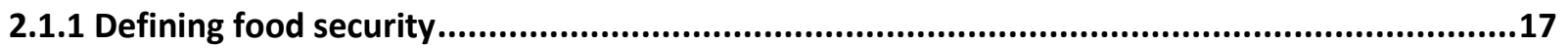

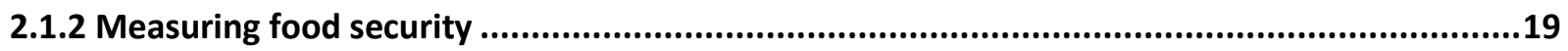

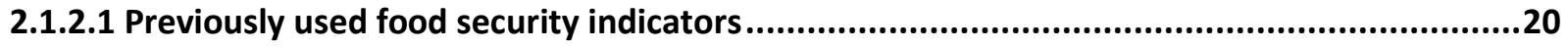

2.1.2.2 Experience-based scales...............................................................................................22

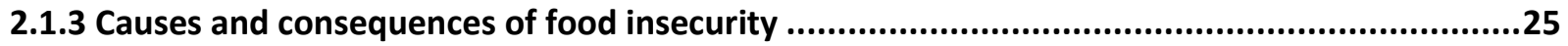

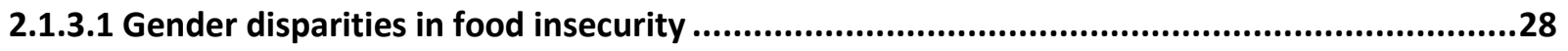

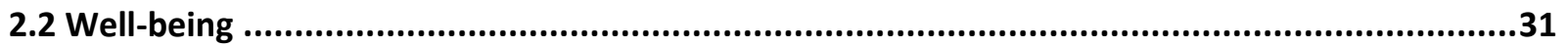

2.2.1 Defining life satisfaction from well-being ......................................................................33

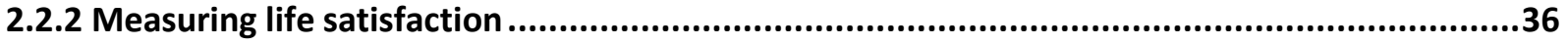

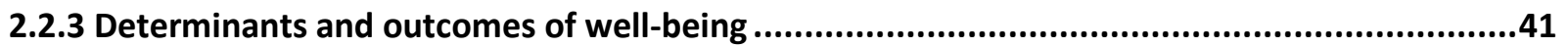

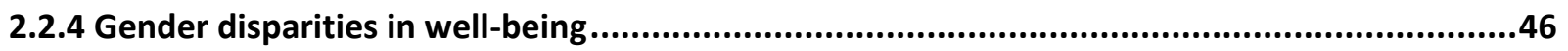

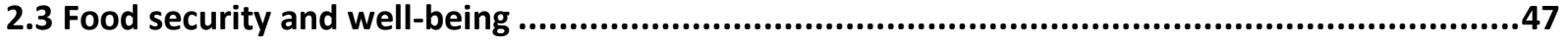


Chapter 3: General methodology .......................................................................................... 49

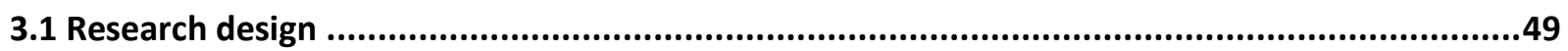

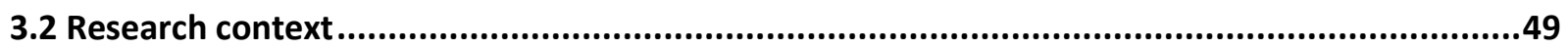

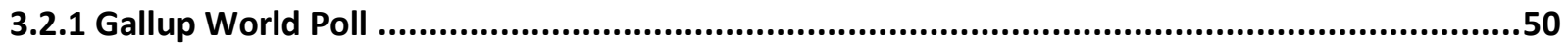

3.2.2 The Food Insecurity Experience Scale ...............................................................................51

3.2.3 Using Rasch modeling and Item Response Theory..........................................................53

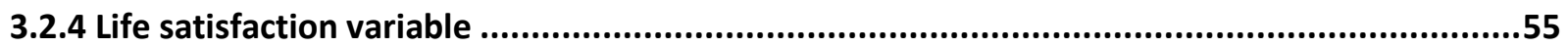

3.3 Sampling and survey methodology of the Gallup World Poll ..................................................56

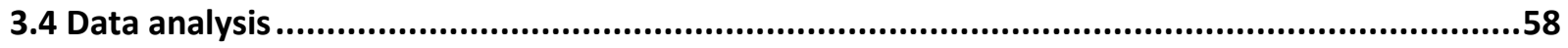

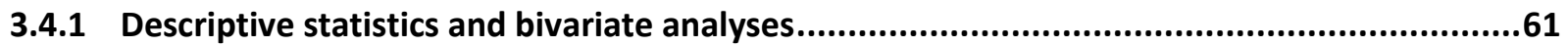

3.4.2 Multiple logistic regression models..................................................................61

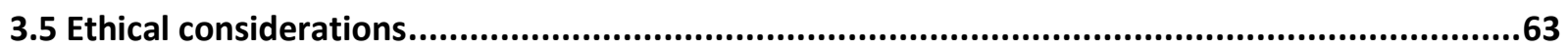

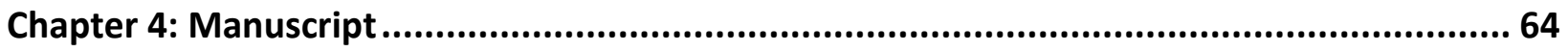

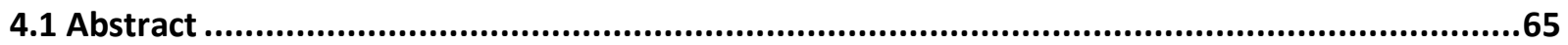

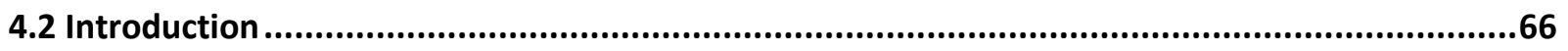

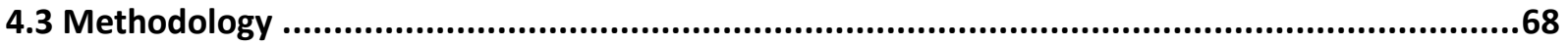

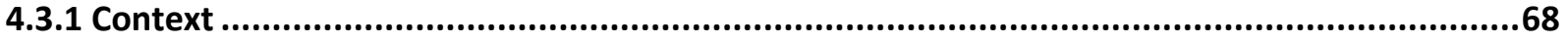

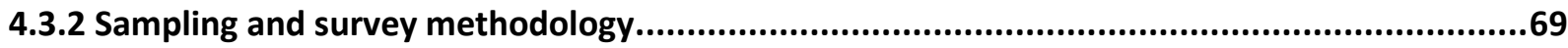

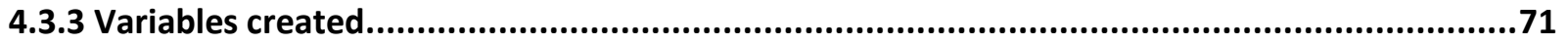

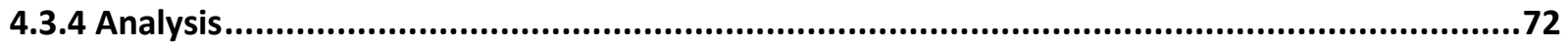

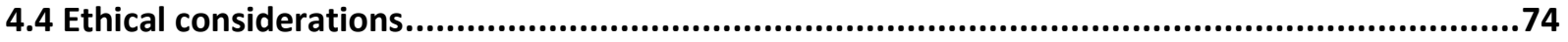

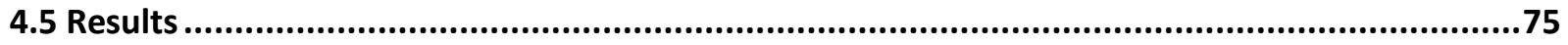

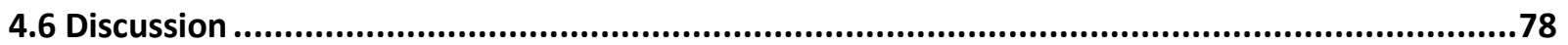

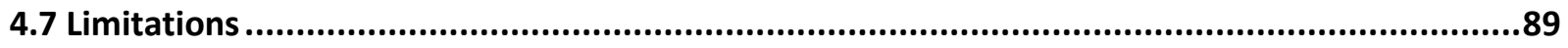

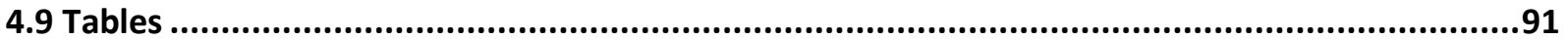

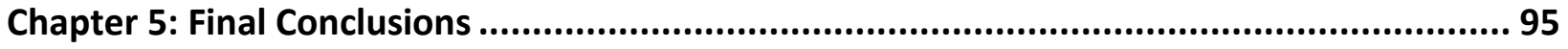

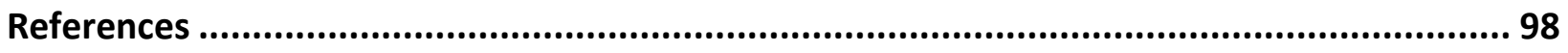

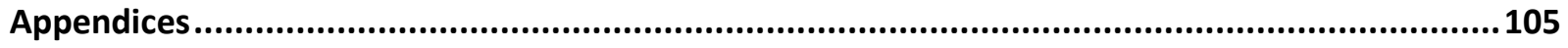




\section{List of tables}

Table 3.1 Life satisfaction variable, adapted from Gallup methodology (GWP, 2009)

Table 4.1 Characteristics of the sample (weighted)

Table 4.2 Bivariate analysis of sample characteristics by food insecurity status

Table 4.3 Bivariate analysis of sample characteristics by gender

Table 4.4 Bivariate analysis of sample characteristics by life satisfaction category

Table 4.5 Logistic regressions OR for food insecurity by gender

Table 4.6 Logistic regression, unadjusted and adjusted OR for life satisfaction

\section{List of figures}

Figure 2.1 Scale of food insecurity severity (FAO Voices of the Hungry project website)

Figure 2.2 Food security determinants conceptual framework (Perez-Escamilla et al., 2008)

Figure 2.3 Trends in subjective well-being and GDP in Egypt (OECD, 2013)

Figure 2.4 World distribution of Cantril ladder, 2005-2011 (Helliwell et al., 2012)

Figure 2.5 Features that determine a person's well-being (Helliwell et al., 2012) 


$\begin{array}{ll}\text { Abbreviations } \\ \text { ELCSA } & \begin{array}{l}\text { Harmonized Latin American and Caribbean Food Security Scale (from the } \\ \text { Spanish, Escala Latinoamericana y Caribena de Seguridad Alimentaria) }\end{array} \\ \text { ESS } & \text { European Social Survey } \\ \text { EVS } & \text { European Values Survey } \\ \text { FAO } & \text { Food and Agriculture Organization of the United Nations } \\ \text { FIES } & \text { Food Insecurity Experience Scale } \\ \text { GWP } & \text { Gallup World Poll } \\ \text { HFIAS } & \text { Household Food Insecurity Access Scale } \\ \text { LMIC } & \text { Low and Middle Income Countries } \\ \text { MDG } & \text { Millennium Development Goals } \\ \text { SDG } & \text { Sustainable Development Goals } \\ \text { US HFSSM } & \text { United States' Household Food Security Survey Module } \\ \text { WVS } & \text { The World Values Survey }\end{array}$




\section{Chapter 1: General overview}

\subsection{Introduction}

Food is an integral part of the overall well-being of individuals and populations. It is vital for a productive life and a sustainable economy, yet no country worldwide can claim complete food security for each of its citizens. Although it has been widely accepted that there is enough food produced globally to meet the world's population needs (WFP, 2011), hunger remains a chronic problem, with increased strain in developing countries (Gebrehiwot, T., \& Van der Veen, A., 2014). Tens of millions of people around the world do not have access to enough food for an active and healthy life.

Fostering food and nutrition security stands as a moral duty, but also as a legally binding human rights obligation. Adequate food was declared a basic human right over half a century ago and enshrined in Article 11 of the 1976 International Covenant on Economic, Social and Cultural Rights (UN Human Rights, 1976; Office of the UN High Commissioner for Human Rights, 2010). Regional treaties formed to protect this right, often targeting vulnerable groups such as elderly, women, and minorities, and many national constitutions have vowed to uphold access to food for their citizens. In 1996 the World Food Summit established the currently most cited definition of food security as, "when all people, at all times, have physical, social and economic access to sufficient, safe and nutritious food which meets their dietary needs and food preferences for an active and healthy life (Food and Agriculture Organization of the United Nations, 1996). 
The demand for measures of food security that reflect the complex dimensions of food availability, access, utilization, and stability has pressed on since 1996, and is still not yet adequately fulfilled (Cafiero et al., 2014). The need to go deeper than national level when assessing food insecurity has driven an increased use of population surveys that can better reflect direct evaluations of a household or individual's access to food, compared to national food balance sheets and other macro-level assessments. Experience-based food insecurity scales emerged in recent decades to capture a broader concept of food insecurity.

Approaching the food insecurity situation from a behavioral perspective, ethnographic research carried out in the United States in the early 1990's revealed different experiential domains as defining characteristics of household food insecurity- uncertainty and worry about food, consumption of low-quality food or unbalanced diets, and at most severe level, reductions in the quantity of food consumed (Radimer et al., 1990). Comprising questions that assess these behavioral domains, many established scales such as the U.S. Household Food Security Survey Module (USDA, 2014), the Household Food Insecurity Access Scale (Coates et al., 2007), and the harmonized Latin American and Caribbean Food Security Scale (Pérez-Escamilla et al., 2007), served as a model for the creation of the Food Insecurity Experience Scale (FIES) developed by FAO in 2013 (Ballard et al., 2013).

Research measuring people's perceived wellbeing, similar to measuring experienced food insecurity, is a relatively young endeavor. Numerous measures of subjective well-being exist, most falling between two distinct groups, cognitive life evaluations (life satisfaction measures) 
and measures of affect. Psychology researcher Hadley Cantril is well known for his contribution to the 'life evaluation' research methods, via his 12 country data collection between the years of 1957- 1963 using his self-designed "Self-Anchoring Striving Scale", which asked respondents their perceptions of where they stood on a hypothetical ladder at three different points of time (Cantril $H, 1977)$. In the +50 years since Cantril's famous survey, researchers in many fields such as education, medicine and social sciences have adapted the scale to measure life satisfaction and its relationship to other research aspects. Most of these revised life satisfaction measures have been carried out using the individual as unit of analysis, allowing for gender disparities exploration. It has been noted in most high-income countries, women report higher life satisfaction and happiness [measures of affect] than men (Helliwell et al., 2012). To date, the Gallup World Poll ${ }^{\circledast}$ (GWP) provides the broadest country coverage using an individual-level adapted version of the Cantril scale.

\subsection{Study rationale}

Research analyzing the link between food security and perceived life satisfaction (and other self-reported well-being measures) is needed for all members of society to prosper through effective policy making, yet is still in its infancy.

Although life satisfaction is indeed a subjective experience, years of research from psychologists, economists, pollsters, sociologists, and others have shown that it can be objectively measured, assessed, correlated with observable brain functions, and related to the characteristics of an individual. Measuring life satisfaction in conjunction with experience-based 
food insecurity measures stands to offer invaluable information about a society, signaling underlying crises or early warnings. Further, combining these measurements can highlight resiliencies and unknown strengths of populations in challenging situations.

Assessed at the individual level, measuring life satisfaction alongside food insecurity can foster a deeper and more complex understanding to the way men and women can have different experiences between and within food insecurity severities. In 2009 it was reported that $60 \%$ of the global undernourished population was comprised of women or girls (Asian Development Bank, 2013), illustrating a consistent over-representation of women in the food insecure population. The need for accurate measurement of food insecurity and well-being is evident, and requires a change in approach to how men and women are appropriately represented.

\subsection{Overall study aim}

The purpose of this study is to explore how an individual's gender influences the likelihood of experiencing food insecurity, and how food security and life satisfaction interact with each other.

\subsection{Study objectives and hypotheses}

The primary objective of this study is to analyse whether gender is a global risk factor for being food insecure. The primary hypothesis is that women will be more likely than men to be food insecure. 
The secondary objective of this study is to explore the relationship between food insecurity and reported life satisfaction, and how that relationship may be more pronounced for men or women. The secondary hypothesis is that food insecure men will be more likely than food insecure women to report higher perceived life satisfaction.

\section{Chapter 2: Literature review}

\subsection{Food security}

Food insecurity is a multi-faceted problem, existing in every region of the world. Research on the consequences of food insecurity has grown robust in recent decades, however food insecurity remains a difficult experience to define and to measure on a global scale.

The term 'hunger' has often been used synonymously with food insecurity, often to inspire action or campaigns aiming to combat it. Indeed, 'hunger' speaks powerfully and clearly to a worldwide audience, especially when discussing issues as complex as food insecurity (Cafiero, et al. 2014). The distinction should be made, however, that these terms are not interchangeable and that the term 'hunger' often describes a particular range of situations from short-term physical discomfort to severe life-threatening lack of food (Von Grebmer et al., 2014). Hunger is indeed part of food insecurity, and is often noted throughout food security policy and program design, but it does not represent the full construct of how food security is currently defined. 
Efforts such as the United Nations Millennium Development Goals (MDG), a product of the 2000 United Nations Millennium Declaration adopted by the General Assembly (United Nations Millennium Declaration, 2000), pronounced "Men and women have the right to live their lives and raise their children in dignity, free from hunger..." The number one MDG professes to eradicate extreme poverty and hunger, with a target to half the proportion of people who suffer from hunger by 2015. While the proportion of undernourished people globally decreased, with the decline most pronounced in developing regions, an estimated 795 million people continued to suffer from malnutrition and hunger (FAO, IFAD and WFP, 2015).

The term 'malnutrition' is used currently in a way that encompasses the 'hunger' component previously discussed, and is thus a central factor within food insecurity. However, malnutrition is recognized to have many forms, many of which have been found to coexist in the same populations. These various forms of malnutrition include child undernutrition, child and adult micronutrient deficiencies, and child and adult overweight and obesity (International Food Policy Research Institute, 2014). The poorest members of a community can lack an adequate supply of energy, protein and micronutrients, while those better-off members of a community who can access sufficient calories will often experience overconsumption and/ or poorlybalanced diets. With global shifts in what and how people are eating, we see that more than one type of malnutrition can exist with a country, community and even a single household (FAO, IFAD and WFP, 2013). 


\subsubsection{Defining food security}

Food security is currently defined as existing "..when all people, at all times, have physical, social and economic access to sufficient, safe and nutritious food that meets their dietary needs and food preferences for an active and healthy life," (FAO, 1996). Food security is vital for an individual to maintain an optimal nutritional status, requiring not only sufficient quantities of food (with regard to calories), but also to sufficient quality (with regard to variety and micronutrient content). Without any one of these dynamic components, including cultural acceptability of the food and how it was procured, food insecurity can occur.

To better conceptualize food security, FAO adopted the 4 pillars of food insecurity, in hopes that efforts through each specific dimension could address specific scopes of the injustice (FAO, 2006):

Food Availability: referring to the physical availability of sufficient quantities of food, also being of appropriate quality, that are supplied through a variety of ways, such as domestic production, imported foods, and food aid.

Food Access: referring to the ability of individuals to access adequate resources (also called entitlements) for acquiring appropriate foods for a nutritious diet. Entitlements are defined as a set of all commodity bundles over which a person can establish command, given the legal, political, economic, and social arrangements of the individual's community. This could include traditional rights of that particular individual, such as access to common resources. 
Utilization: referring to the utilization of food through adequate diet, clean water, sanitation and health care, all required to reach a state of nutritional well-being where all physiological needs are met. This pillar highlights the importance of non-food inputs in food security.

Stability: referring to a population, household, and individual's need to have access to adequate food at all times. To live a food secure life, populations should have infrastructure to efficiently adapt to sudden shocks (for example, an economic or climatic crisis) or cyclical events (for example, seasonal food insecurity). Therefore, the stability dimension underlines both the availability and access dimension of food security.

To further understand the diverse situations of food insecurity, distinctions have been established between the varying durations of food insecurity experience. Much of the literature defines three distinct groups that should be approached uniquely (WFP, 2009):

Chronic food insecurity: referring to a long-term or persistent inability to meet the minimum food consumption requirements for an active and healthy life. The situation can be considered 'chronic' if food insecurity lasts for at least six months in a year.

Transitory food insecurity: referring to a short-term or temporary inability to meet the minimum food consumption requirements for an active and healthy life. The situation can be considered 'transitory' if the short periods of food insecurity relate to sporadic crises. 
Cyclical food insecurity: referring to a habitual seasonal variation of the food insecurity situation. This group can run concurrent to 'chronic', if seasonal (cyclical) food insecurity is present for more than six months of a year, or as 'transitory', if it lasts for less than six months of a year.

While these definitions can help localize efforts and policy targeting, it is also important to maintain a big-picture perspective relating to transitory and chronic consequences. Failing to address food insecure events with both timelines in mind can have potentially negative effects on long-term food security, such as manifested dependencies, or weakened local markets particularly in low-income areas (Webb et al., 2006).

\subsubsection{Measuring food security}

Efforts to measure, monitor, and eradicate food insecurity have been underway for decades, with specific approaches emerging from varying sectors: economy, agriculture, policy, health and nutrition. Although it is widely acknowledged that food insecurity exists within low-income countries, the exact number of food insecure individuals, and the extent to which they suffer, remains unspecified within countries (Cafiero et al., 2014). It is therefore essential to use reliable measurements to estimate the extent of food insecurity at the individual level. To date, there is no "gold standard" for measuring food insecurity (Coates et al., 2006), and so an array of measurement instruments are needed to account for the phenomenon and to monitor the multiple dimensions. 


\subsubsection{Previously used food security indicators}

Until recently, regional and national-level assessments using economic indicators of food availability, food production, and income had been used to measure food security. These measures give a large-scope perspective of a population's food availability, but do not evaluate the experience of food insecurity for households or individuals (Melgar-Quiñonez, H. \& Hackett, $M, 2008)$. Further, these measures are often fiscally expensive as well as time consuming to administer and analyse.

Two indicators were elected to monitor the progress toward achieving the first Millennium Development Goal (MDG), to halving the proportion of people who suffer from hunger by 2015.

The first, FAO's Prevalence of Undernourishment indicator, is an estimate of the number of people who are likely not ingesting enough food to meet dietary energy needs, based on national estimates of total food energy available for human consumption, and distributions of energy requirements and consumption in the population (FAO, 2012). The POU measure is statistically complex to calculate, and is largely dependent on national capacity to reliably collect and report data. While the POU can be used to appropriately monitor national and regional trends in undernutrition related to estimates of needs, it does not identify who the food insecure are, or where they live within each country (Cafiero et al., 2014), and thus is not a direct indicator of access to food at the household or individual level. From a gender perspective, the PoU cannot be used to investigate if women are more likely than men to be 
undernourished, nor explore under which food-adverse conditions this happens (Brunelli et al., 2014).

The second indicator used to monitor the MDG regarding hunger is weight-for-age (measure of underweight) of children under five years of age. This anthropometric measure (along with height-for-age, measure of stunting) provides invaluable information regarding the nutritional status of children. However, similar to the POU, using anthropometric measures such as underweight or stunting is costly and requires a sophisticated level of data collection expertise, as they are a direct measure of another condition closely associated with food insecurity: malnutrition.

As previously discussed, the term malnutrition refers to both undernutrition (nutritional deficiencies) as well as overnutrition (consumption of too much energy in relation to individual requirements) although previous literature commonly associated the term malnutrition with undernutrition (Frongillo, 2003). As the nutrition transition has become increasingly evident, comprising a decreasing prevalence of undernutrition and increasing rates of overweight among low income or less privileged groups, these measurement tools and preconceived assumptions regarding the association between poverty, hunger, and undernutrition are being re-evaluated worldwide (Monteiro et al., 2004). Due to the complex relationship between food security and underweight, as well as overweight, the use of anthropometric measures as proxy indicators of household or individual-level food security has been recently challenged (Frongillo, 2003). 


\subsubsection{Experience-based scales}

In the 1990's, ethnographic research was carried out in Upstate New York, USA, to better understand the lived experience of hunger. The first research of its kind, Kathy Radimer and her team at Cornell University revealed hunger to be a process characterized by initial worrying about having enough food to eat, followed by dietary changes to make limited food resources last, and finally, decreased consumption of food in the household (Radimer et al., 1992). These findings stemmed a new approach to conceptualizing the experience of hunger, and along with other researchers in the mid 1990's, coincided with nations' increasing focus on unequal access to food and socio-cultural aspects of the experience of hunger (Sen A. 1981).

This conceptual approach to food insecurity as an experienced phenomena paved the way for experience-based food insecurity scales to be used, validated early on by comparable patterns found in U.S. elderly food insecure populations, as well as low-income families in Quebec, Canada (Hamelin et al., 2002). Although the original Radimer et al. study used a small number of households in a high-income country (USA), a 2006 review of studies spanning countries in different regions of the world concluded that these dimensions of worry, dietary changes in variety, and decreased dietary consumption, appear to be common across cultures (Coates et al., 2006).

The unique contribution of experience-based food insecurity scales is the ability to capture psychosocial aspects, such as anxiety or uncertainty, as well as behaviors relating to the ability 
to procure enough food at the individual level. Experience-based food insecurity scales are comprised of questions that ask people directly to report their behaviors or experiences related to obtaining food of sufficient quality and quantity due to limited money or other resources (Voices of the Hungry, 2014). Each question will typically address a different situation and is associated with a level of severity according to the theoretical construct of food insecurity underlying the scale.

\section{Figure 2.1 Scale of food insecurity severity (FAO Voices of the Hungry project website)}

Mild food insecurity

Uncertainty regarding

ability to obtain food
Compromising on food quality and variety
Reducing food quantities, skipping

meals
Severe food insecurity

Experiencing hunger

This underlying theoretical construct of food insecurity formed the basis for the U.S. Household Food Security Survey Module (USDA, 2014), which since 1995 has been applied annually to monitor the food security situation in the United States (Ballard et al., 2013). The US HFSSM served as a model for many other experience-based food insecurity scales around the world, and offered a significant change in the approach to measuring food insecurity at the time.

Some prominent scales that have been adapted from the US HFSSM include the FANTA Household Food Insecurity Access Scale (Coates et al., 2006) and the FANTA Household Hunger Scale (Ballard et al., 2011). Also stemming from the US HFSSM, the Latin American and Caribbean Food Security Scale (Escala Latinoamericana y Caribena de Seguridad Alimentaria, or 
ELCSA) was constructed in the early 2000s from a regional collaboration to create a food insecurity measure that combined the experiences of several Latin American nations. The ELCSA incorporated aspects from the Brazilian Food Insecurity Scale (a similar scale adapted for Colombia), as well as the Household Food Insecurity Access Scale (HFIAS), which was developed by the U.S. Agency for International Development (Coates et al, 2007). Thus, the ELCSA was created from the combined experiences with food insecurity scales in various countries, also reflecting the growing demand for tools that could diagnose and monitor food insecurity relatively quickly and with ease of administration over multiple nations.

The Food Insecurity Experience Scale (FIES) is the global version of the first eight questions of the ELCSA, adapted originally for use at the individual level. The FIES is based on the premise that the evidence of universal dimensions of experienced food insecurity (Swindale, A. \& Bilinsky, P., 2006), as well as accumulated research showing the cross-cultural validity and applicability of measures which preceded the FIES, support the use of a standardized measure that enables international comparisons. One major advantage of using the FIES is its capacity to compare food secure severities across population groups, including gender (Brunelli et al., 2014). An important pre-requisite towards developing a tool measuring severity of food insecurity in a comparable way worldwide is careful linguistic adaptation, which was undertaken by FAO in 2013 as part of a 4-country pilot study.

While considerable evidence points to the validity and reliability of experience-based food insecurity scales in diverse contexts, the evolution continues with regards to labeling these 
measures. During the proceedings of the 2002 International Scientific Symposium at FAO, experience-based scales were referred to as "qualitative measures" (FIVIMS, 2002). Often, there is a severe distinction made between "objective/ quantitative" and "subjective/ qualitative" schools of thought (Webb et al., 2006). Experience-based food insecurity scales are sometimes referred to as qualitative approaches, due to the experience of food security not being directly quantifiable (in the sense of directly observing or counting something). This study argues that experience-based scales may be considered subjective measures only in the sense

that they are based on self-reporting, as is the case for much health, social, employment and fiscal data currently collected through survey methods.

\subsubsection{Causes and consequences of food insecurity}

Causes of household and individual food insecurity, as well as the consequences for individual health and well-being, can be viewed through local, regional, national and international lenses. 
Figure 2.2 Food security determinants conceptual framework (Perez-Escamilla et al., 2008)

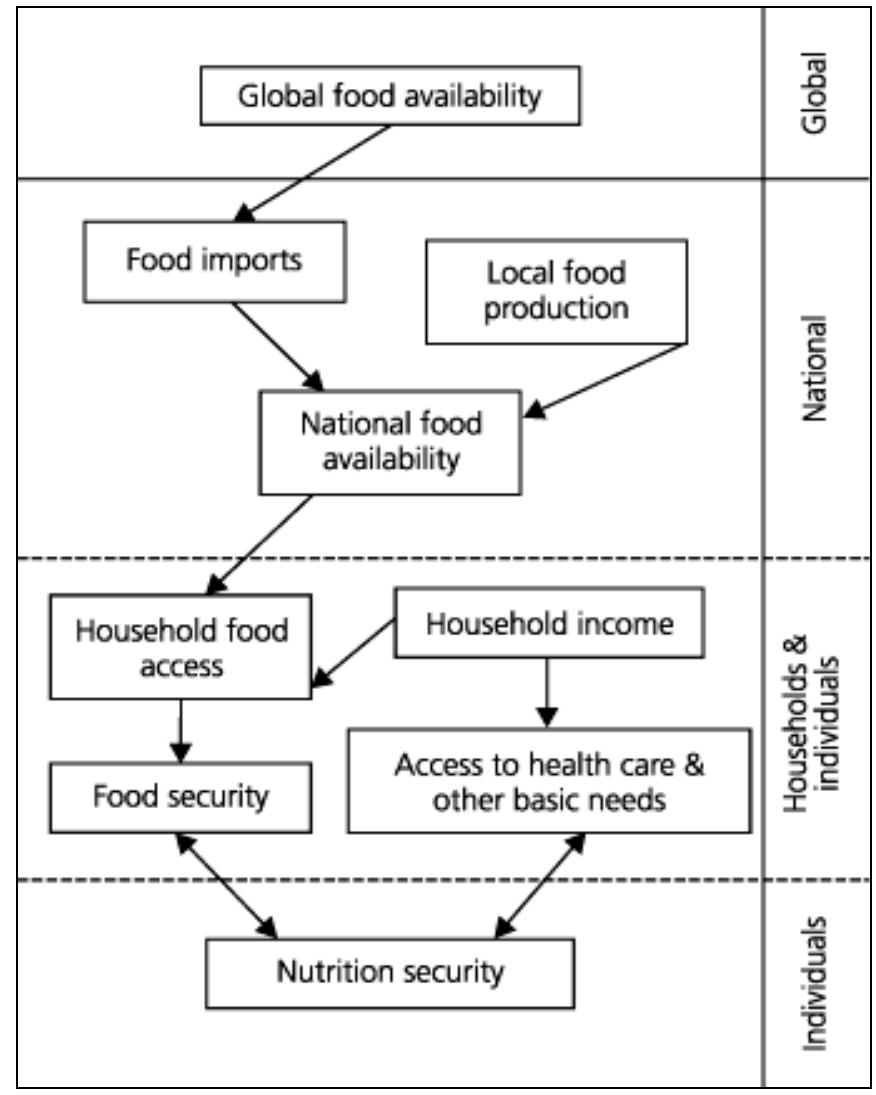

At differing levels of severity, food insecurity can be linked closer to specific pillars comprising food security. At the global level, the elemental pillar is availability: does global agricultural activity produce enough food to feed the world's population? In 2015 , the answer to this question was yes (WFP, 2011), though developing nations and rural areas of some developed countries still faced serious threats of hunger (Gebrehiwot, T., \& Van der Veen, A. 2014). Further, given the trend of a growing world population, declining soil productivity and biodiversity quality, increasing use of land for fuel rather than food, and insufficient attention to climate change mitigation and sustainable agriculture development, as well as other factors, global availability may not remain as it is for long (Brown et al, 2008). 
Analyzing food security at the national level requires an understanding of national production (availability), but also the nation's access to food from the global market, foreign exchange earnings, and its citizens' consumer choices (Zakari et al., 2014).

When we analyse at the household level, food insecurity measurement must reflect a household's own food production, household members' ability to purchase food in light of quality and preference, as well as diversity in the local market place. Many other factors have been shown to affect the status of food security at household level, including household size, poverty status, income, age, ethnicity group, as well as mother's education level (MelgarQuinonez et al., 2008; Zakari et al., 2014).

It has been claimed that only at the individual level can food insecurity be accurately measured, because only through understanding the individual's food access and consumption can we appreciate the impact of sociocultural and gender inequalities on people's ability to meet their dietary needs (Brown et al, 2008). Focusing on the 'utilization' pillar can translate the food available to a household into what nutrition is distributed to its members. Factors influencing individual-level food insecurity can include unhealthy environments, such as poor hygiene and sanitation, often resulting in frequent illnesses and therefore compromised nutritional states, despite sufficient food being available at the individual, household and national level (Brown et al., 2008). In low-income and agricultural-dependent communities, an additional risk for food insecurity exists for infants and young children whose mothers perform agricultural work out of 
necessity to make ends meet, and are often unable to feed their children as often as necessary to provide good nutrition, especially during peak agricultural periods.

\subsubsection{Gender disparities in food insecurity}

It has been shown in previous decades that women and girls are overrepresented among the global food-insecure population. Worldwide, an estimated $60 \%$ of undernourished people are women or girls (United Nations Economic and Social Council [ECOSOC] 2007).

Although nutritional standards (or dietary recommendations) exist for the actual nutritional needs of men, women, boys, and girls of different ages and physiological states (for example, pregnancy and lactation) these recommendations are not universally adhered to, often due to cultural practices and personal beliefs. In South Asia, studies have shown that women are served and/ or eat after everyone else in the household, and are less likely than men in the same household to consume preferred foods such as meats and fish, which are often the most nutrient-dense (Brown et al., 2008). The same Brown (2008) study also found that during times of crisis in low income countries, women and girls are often expected or forced to reduce their intake of higher quality foods or total food quantity in favor of other household members, particularly men and boys.

A study using datasets from the 2001-2008 National Health and Nutrition Examination Surveys (NHANES) shows intra-household differences in food security, consistent with the prevailing literature: U.S. women were more likely to experience food insecurity than U.S. men of similar 
age in households with the same food insecurity and income (Nord, 2011). This finding supports the idea that the number of individuals in food insecure households should not be used to represent the number of food insecure people (Brunelli et al., 2014), and that individual-level food insecurity measures are necessary for exploring the true number of food insecure people. Similar analyses were conducted in adolescent populations in Southwestern Ethiopia (Hadley et al., 2007), where girls were more likely than boys to experiencing food insecurity in food insecure labeled households.

The ways in which women and girl's food security are affected external of the household can be described through their limited access to education and employment opportunities (Asian Development Bank, 2013), which can stunt their economic autonomy and weaken their bargaining position within the family and community. Women's weaker decision-making can translate into little or no voice in household decisions, observing differential feeding and caregiving which favor boys and men, experiencing food and nutrition insecurity, and potentially poorer health and nutrition outcomes (Asian Development Bank, 2013).

Furthermore, women and girls worldwide face constraints related to food production, which are often embedded in social norms and cultural practices, and possibly enforced through national legislation (Doss, 2011). Some laws, such as those governing access to land, include inequitable and exclusionary practices. Doss (2011) found that these unequal rights can negatively affect women's food production, as they are less likely to own land and usually enjoy only 'use' rights, mediated through a male relative. These limitations can affect not only the 
woman's food security and nutrition, but all household members who are dependent on that woman for cash income or food supply.

Although it was widely quoted and used to justify previous gender-sensitive programming, FAO's 1997 claim, "Women produce between 60 and 80 percent of the food in most developing countries and are responsible for half of the world's food production (FAO, 1997)," has since been largely unsupported by reviews (Doss, C., 2011). Doss as well as many other researchers argue that women do not, in general, produce food separately from men, and so this claim is not empirically valid. For example, if men provide labor to clear a field, and women planted and weeded the crops, and both men and women were involved in harvesting, how should we measure the output produced by women? We must note that women are not the majority of those reportedly working in agriculture (FAO, 2013). However it is still an important sector for female livelihood; of those women who reported being employed in $2010,79 \%$ in the least developed countries, and $48 \%$ worldwide, reported agriculture as their primary economic activity (FAO 2013). Worldwide, as men move to non-farm jobs, more and more agricultural work is being done by women. It has been shown that in all regions of the world, except Europe, the proportion of women in the total agricultural workforce has risen over the past 40 years (Doss D., 2011).

Given the asymmetries in ownership of, access to, and control of livelihood assets (such as land, water, energy, credit, education and labor) as well as the primary responsibility for many other household tasks as well, women's food production and overall well-being is frequently in 
jeopardy. There is a lack of research engaging with gender roles in agriculture and how they change over time, especially in response to new economic opportunities and employment shifts for men and women.

\subsection{Well-being}

To date, well-being has been assessed through different sectors using various stylistic approaches. Most experts define subjective well-being as covering a number of different aspects of a person's subjective state, though the current literature still debates on which elements should be included in this core set of aspects (OECD 2013). Components commonly used for global well-being assessments are perceptions of economic status, physical and mental health, family circumstances, and human and political rights (Deaton, A., 2008), supporting the common hypothesis that a wide range of functions and capabilities will determine if people are able to lead a good life. The OECD provides a relatively broad definition of subjective well-being for their 2013 Guidelines, “..Good mental states, including all of the various evaluations, positive and negative, that people make of their lives, and the affective reactions of people to their experiences."

The broad nature of OECD's definition may create the illusion of well-being as an awfully vague concept. However, there is general agreement in the well-being field of two distinct sides that comprise subjective well-being (Dolan \& White, 2007; ONS, 2011): life evaluations and measures of affect. Measures of affect capture feelings experienced at a particular point in 
time, while life evaluations involve a cognitive assessment of the respondent's life as a whole. Life evaluation is the element of subjective well-being that is assessed in this current study.

A previous approach to measuring subjective well-being was to directly and objectively measure each aspect of well-being separately (for example, income, anthropometric measures, educational attainment, and diet). However, this approach has lost steam in favor of measures encompassing the collective and evaluative experience which is considered life evaluation, which current literature supports can aggregate important, overarching aspects of a life into a single summary measure (Layard, Richard. 2005). This will often appear as a one question measure that asks a respondent to consider overall life factors in unison, usually with reference to a numerical scale. For this holistic indicator, surveys can be a useful method as they provide a direct and easily administered measure, where people can report on their own level of life satisfaction (Helliwell et al., 2012).

While well-being is widely considered important to overall welfare, and oftentimes written into policy or even national constitutions, it is an experience that has seemed too vague or imprecise, reflecting a varying notion unable to be reflected in robust measurement and policy. In a recent nation-wide U.S. polling, the general public viewed subjective well-being as something that should be pursued individually, rather than as policy or collective pursuit (Helliwell et al., 2012).

However, decades of research in the fields of psychology, economy, public polling, sociology, 
and many others have shown that well-being, though indeed a subjective experience, can be objectively measured, assessed, correlated with observable brain functions, and reliably reflect the characteristics of an individual and their society (Helliwell et al., 2012). Helliwell (2012) concluded that by asking people directly whether they are happy or satisfied with their lives, underlying crises or hidden strengths can be signaled for social and economic policy consideration. By offering people the chance to report on the quality of their own lives, reflecting their own histories, personalities and preferences, it is possible to observe not what experts or governments think should define a good life, but rather a direct and personal judgment. A fundamental indicator of happiness is how the individual perceives happiness to be, not whether friends see that individual smiling, if relatives believe the person to be happy, or even if all material possessions are measured to be of adequate amount for decent livelihood (Helliwell et al., 2012). Seen in this light, this study argues that the perceived "subjectivity" of well-being is to be seen as strength rather than a weakness in research.

\subsubsection{Defining life satisfaction from well-being}

The two sides of subjective well-being, as described in the previous chapter, can be defined as perceived life satisfaction (life evaluation), and how happy people report feeling [measures of affect] (White et al., 2014). Therefore, it is important to note that life satisfaction and happiness are not synonymous terms (Deaton, A., 2008).

Measures of affect, often called 'experienced happiness', refers to the emotional quality of an individual's everyday experience (Helliwell et al., 2012). This aspect of well-being will often 
explore the lived experience of daily and acute emotions such as joy, anxiety, sadness, and anger by asking the respondent questions with such formats as "Did you smile a lot yesterday," or "Did you feel angry/ safe/ sad yesterday?"

The other aspect of well-being, life evaluation, explores an individual's own perception of his or her overall life (Helliwell et al., 2012), otherwise referred to as "life satisfaction" in the literature. Questions that measure life satisfaction ask respondents to evaluate their lives overall, without offering a timeframe or asking for specific emotional experiences. This type of measure is viewed as a judgment by the respondent, not a description of an emotional state.

Research of both qualitative and quantitative nature has examined how the same samples can often report on experienced happiness and life satisfaction in differing ways (Larsen et al., 1985), which leads to different correlations between the two measures (Kahneman, D., Deaton, A., 2010). For example, when people are asked about their happiness now or yesterday, answers are generally tied to current activities and events. In contrast, when people are asked about how satisfied they are with their lives these days, answers match closely to other major life factors such as employment or health status.

Additionally, life evaluation measures have been shown to capture how people remember their experiences, and therefore may differ from how people actually experienced events at the time. To conceptualize this phenomena, we may consider the "peak-end-rule" which argues that a person's evaluation is based on the most intense (peak) emotion, and by the last (end) 
emotion, rather than the average or integral emotional experience (Kahneman et al., 1993). Even with this theory in mind, life evaluations have been shown to capture decision-making constructs, aligning closely to the individual welfare construct that is grounded in the conventional economic paradigm (OECD, 2013). This reinforces that life evaluations are of paramount interest for researchers and policy-makers aiming to support the well-being of society.

Measures of subjective well-being provide an alternative yardstick of progress that is grounded in people's experiences, oftentimes differing from other important, conventional metrics that focus on access to resources (Helliwell et al., 2012). This disparity is desirable, as it offers nuanced evidence a part from the economic and social indicators such as income or employment typically used to assess a person's welling.

An illustration of this can be seen in the case of the GDP growth and the "Arab Spring", a revolutionary wave of demonstrations and protests in parts of the Arab world against oppressive rule surrounding the years 2010 - 2012. In 2008 - 2010, the two years leading up to the Arab Spring, real GDP per capita increased 7\% in Tunisia from 2008-2010, however the proportion of the population indicating a high level of life satisfaction fell from $24 \%$ to $14 \%$. Egypt showed a similar pattern from 2005-2010, with a real gain in GDP per capita around 34\%, and a decline in respondents reporting a high life satisfaction by almost half (OECD, 2013). For policy-makers, subjective well-being measures are valuable indicators that can alert them to 
culminating and devastating public issues that other economic indicators might fail to identify, which can save community infrastructure and human lives.

Figure 2.3 Trends in subjective well-being and GDP in Egypt (OECD, 2013)

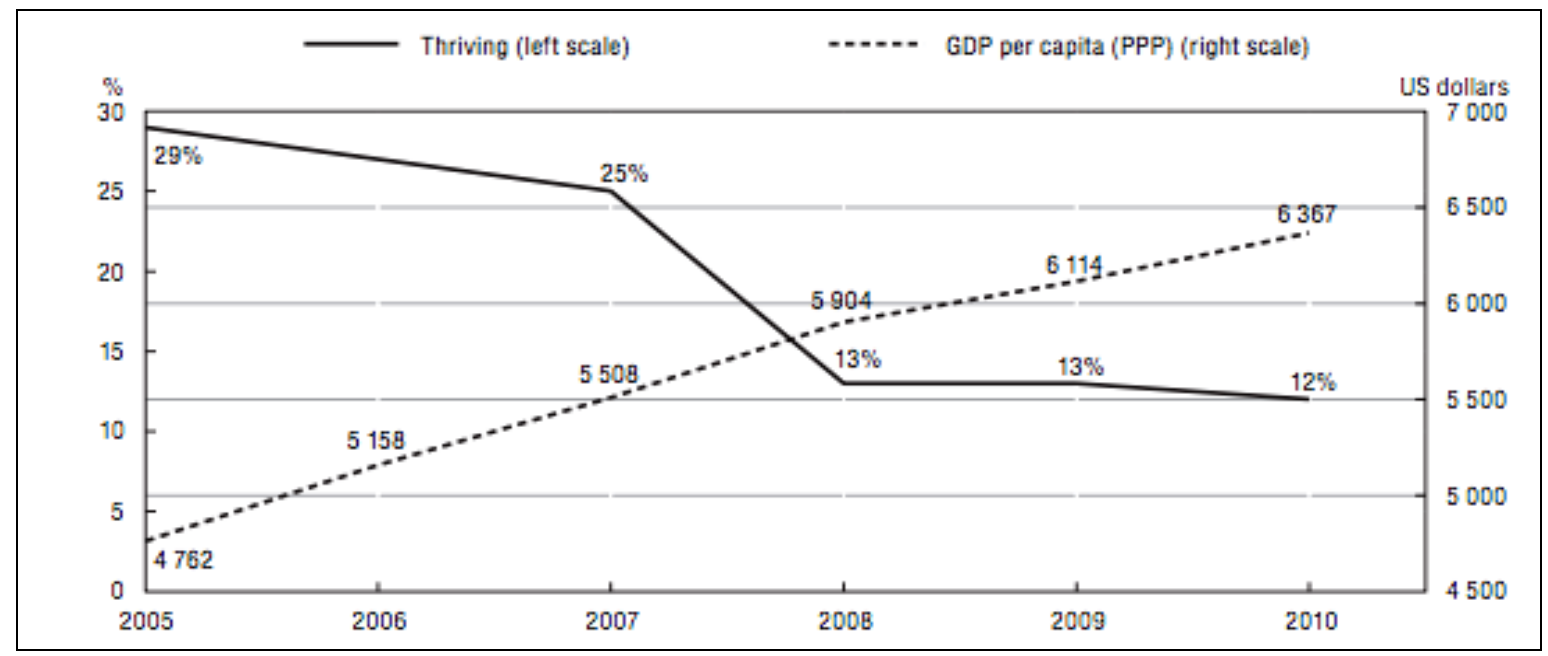

\subsubsection{Measuring life satisfaction}

When looking at life satisfaction as an indicator of subjective well-being, researchers have used a myriad of question structures. Recent life evaluation measures have used a variation of the question, "How satisfied are you with your life as a whole these days?" (Kahneman, D., Deaton, A. 2010). However, many international public opinion surveys, such as the GWP (Gallup, 2009), The World Values Survey (WVS, 2015), the European Values Survey (EVS, 2014) and the European Social Survey (ESS, 2015), adapted a variation of the Cantril Self-Anchoring Striving Scale, often referred to as the Cantril Ladder. In the first decades of using this measure, it was reported that the Cantril Ladder had weaker psychometric properties as well as low reliability, some reporting in the $0.3-0.5$ range (Larsen et al., 1985). The most common explanation for the low reliability of the Cantril Ladder cited the single item measure as a significant limitation. 
Nevertheless, it was concluded by Kahneman \& Deaton (2010) that the Cantril ladder was a pure measure of life evaluation, and in 2010, Kahneman and Deaton considered the Cantril ladder a serious global contender for the best tool for measuring the degree to which individuals view themselves as achieving their overall goals, both material and other.

The Cantril Ladder represents a self-perceiving well-being measure that has been used in both low and high-income nations. Hadley Cantril and his assistants conducted the Pattern of Human Concerns study based on data from 18 countries, between 1957-1963, in partnership with the Institute for International Social Research and Princeton University. The "Self-Anchoring Striving Scale," an open-ended scale that conceived a ladder with 10 rungs, asked respondents to define his or her greatest wishes and hopes, which would symbolize the top rung. The respondent was then asked to define greatest worries or fears, which would symbolize the bottom rung. This preliminary step for the single item scale is what creates a self-defined spectrum (Cantril, $\mathrm{H}$. 1977). Respondents were then asked to indicate their perception of where they stood on their uniquely constructed ladder at three different points in time: 5-10 years prior, present time, and 5-10 years into the future. 
Figure 2.4 World distribution of Cantril ladder, 2005-2011 (Helliwell et al., 2012)

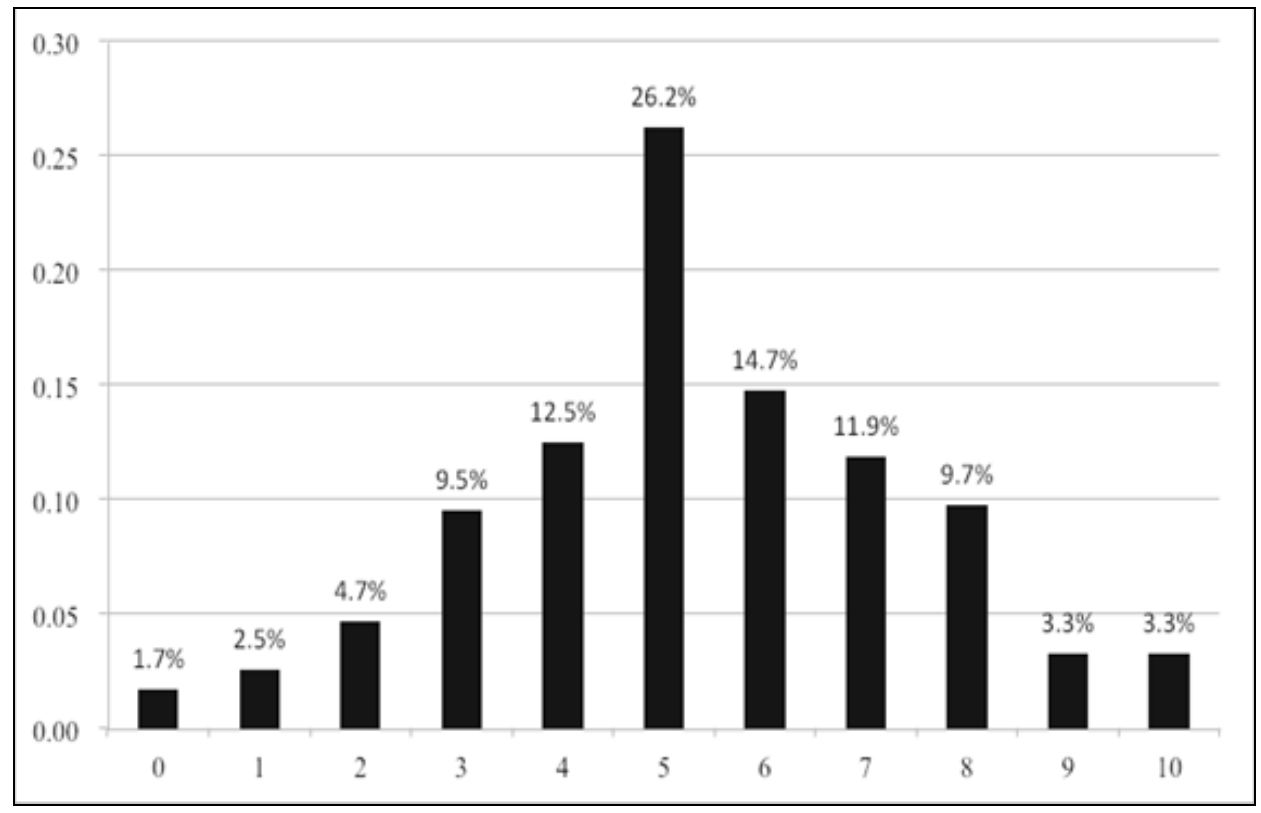

The Cantril Ladder currently covers the widest span of countries of any well-being indicator (Helliwell et al., 2012), and is administered by the GWP. Figure 4 illustrates the distribution of world life satisfaction scores from the years 2005 - 2011. The total height of each bar represents the number of people in the world, aged 15 and older, who gave that numeric score for their life evaluation.

One theory that Hadley Cantril offered following his results during the 1970's, which has been upheld by many well-being researchers since, is that quantitative changes, such as rapid technological advances, are translated by people as changes in their quality of life (Samson, S.A., 1978). Since the 1970 's, the Cantril Ladder has been administered worldwide to aid with various research topics, and questions regarding the validity and reliability of using subjective well-being measures have arose. 
Well-being is most often seen through the scope of psychology, and thus we can infer reliability of the Cantril Ladder by the extent to which it yields identical answers when administered in the same conditions. Subjective well-being measures have been tested for replicability in a variety of ways, and life evaluation approaches in particular (such as the Cantril Ladder) show a decreasing correlation when asked of the same person in a sequence of surveys (Blanchflower et al., 2002). This follows the theoretical expectation previously discussed that life evaluations are largely based on underlying circumstances that will change over an extended period of time. Still, at the group or national level, reliability is very high for measures such as the Cantril Ladder, due to individual-level random variations and personality fluctuations being averaged away, and underlying circumstances that may change from year-to-year changing modestly over longer time frames (Blanchflower et al., 2002; Helliwell et al., 2012).

In the case of validity, subjective well-being measures have been correlated with objective measures such as facial expressions, brain-wave patterns and cortisol measures at the individual level, as well as community and national suicide patterns. Some of the literature argues that these correlations are necessary before considering subjective well-being measures as serious indicators. Yet the coincidental movements of physical attributes, reasoned in the World Happiness Report (Helliwell et al., 2012) are of less consequence compared to the subjective measure of well-being. This subjective perception is the primary element to be described, as certain patterns of electrical activity in the brain only became established as indications of 'happiness' because they tended to be present when people reported in 
subjective well-being assessments that they found themselves to be happy.

A further point to the validity of subjective well-being scales like the Cantril Ladder is the ability of live evaluations in large populations to predict subsequent events, such as suicide frequencies, providing strong evidence that life evaluations are important to affective behavior. The fact that these measures have been shown to be predictive of sickness and death only strengthens the need for collecting such measures within regular health care delivery (Helliwell et al., 2012).

A theorized happiness "set point" has been discussed in the literature, which challenges life evaluation measures by stating that each individual has their own set point based on stable personality traits, consistently returning to that baseline after any life changes. Yet if this were the case, we would not see such large and long-standing international differences in life evaluation; for example, the top ten countries measured by the World Happiness Report (Helliwell et al., 2012) are twice as high as the bottom ten countries, and these differences are largely explained by measured differences in life circumstances. In support of this refutation of a 'set-point', data from a series of Canadian General Social Surveys spanning almost 25 years reveals that francophone residents of Quebec have seen (since Quebec's Quiet Revolution) steady growth in life satisfaction compared to similar samples of other Canadian province residents (Barrington-Leigh, C.P., 2011). Consistent literature shows, therefore, that life satisfaction measures can capture more than temporary departures from personality-driven set 
points, and social changes can cause sustained trends in well-being far beyond those explicable by conventional economic measures.

We can use measures of well-being such as life evaluations to aid a variety of efforts (OECD, 2013):

- map to other outcome measures (for example, food security)

- discover those drivers of subjective well-being

- policy evaluation and cost-benefit analysis, particularly where non-market outcomes are involved

There are limitations to well-being statistics, oftentimes centering on the disadvantage that it is not possible to control for person-specific fixed effects, or rather, personal disposition (Blanchflower et al., 2002). Yet, it is doubtful that human well-being can be understood without, in part, listening to what human beings perceive and report.

\subsubsection{Determinants and outcomes of well-being}

If a society wants to bolster the levels of happiness and combat misery, determinants and outcomes must be identified and measured regularly.

Through the perspective of an individual's predisposition to bias and other latent personality traits, it would be of paramount interest for policy-makers to critically review the environmental aspects of populations, and to understand how big of an effect each of these 
factors has on well-being. However, little research so far has been able to study the effects of differing environmental factors on well-being while holding these latent traits constant. Because of this challenge, research looks to other elements that constitute a person's wellbeing: external features, and personal features.

Figure 2.5 Features that determine a person's well-being (Helliwell et al., 2012)

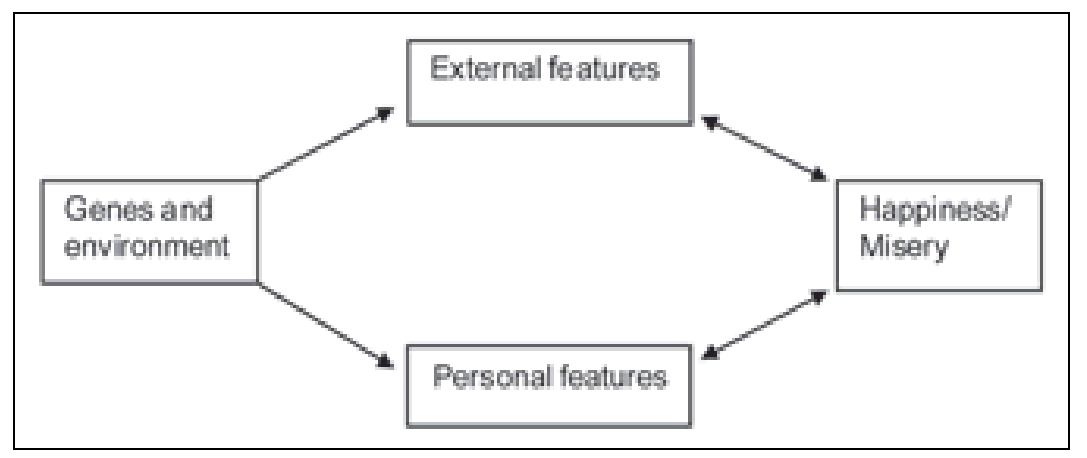

Features that are generally recognized as external can include income, employment, community or governance systems, as well as religion and prevailing cultural values. The personal features category usually includes aspects such as mental and physical health, family and their concerted experience, educational attainment, as well as gender and age.

For economists and policy-makers alike, the role of income on well-being is of continuous interest as there has been the historic assumption that higher incomes translates directly into higher satisfaction. However, recent studies comparing sub-country populations in both low and high-income countries have found only a small effect of income on life satisfaction, relative to other life circumstances (Helliwell, 2003; Blanchflower et al., 2004; Deaton, 2008). 
In short, a household's income is often associated with happiness (Blanchflower et al. 2004), especially within highly developed countries such as the U.S. or UK, however other factors may be more influential to life satisfaction: community trust, employment, mental and physical health, and the quality of governance and rule of law (Helliwell et al., 2012). Raising incomes can raise happiness, most effectively in severe and chronically low-income populations, but fostering these other community-oriented and health-focused factors can do even more, notably in high-income countries that have a low marginal utility of income.

Results from annual studies such as the World Values Survey suggest that the "happiest" countries in the world tend to be high-income countries that also have a high degree of social equality, trust, and quality of governance, such as Denmark, which recently topped the list in 2012. It is not a coincidence then, nor a surprise, that the U.S. has experienced no rise of life satisfaction for 50 years, a time in which income per capita has risen, along with inequality, and social trust and faith in government (based on public polling) has declined (Helliwell et al., 2012).

Studies continue to confirm income as an important indicator for well-being, although the majority of the more recent research stemmed from what has become known as the Easterlin paradox- two facts to explain (though not entirely and not amongst high-income and LMICS alike) income's effect on well-being. These facts, as stated by Easterlin (1974) are:

1. At any point within any society, richer people are on average happier than poorer 
people (cross-sectional)

2. Over time within many societies, the population does not become happier when the society's income rises (time-series)

One reason for the paradox of society's life satisfaction failing to rise with overall income is that individuals compare themselves to others who surround them. Though at any given time, richer individuals are more satisfied with their life than poorer individuals, and thus relative life satisfaction remains unchanged when the society income rises together.

To further clarity, Veenhoven (1991) claims that income undoubtedly improves happiness, until basic livelihood needs are met. Such basic needs include sufficient nutrition, educational attainment, safe childbirth, and stable employment. Beyond this point, where income is high enough so that people do not suffer from hunger, child mortality from preventable diseases is low, and absolute poverty has been eliminated, increases in income do not affect happiness in the same way, nor as drastically. It is reasoned that after basic livelihood factors have been met, happiness varies more with quality of human relationships and health, rather than income.

The relationship between age and evaluations of happiness is a frequently researched aspect within well-being. Although most people would expect that happiness steadily declines with age, as many physical and mental faculties weaken, study results have yet to verify any universal trend. In UK and U.S. populations, there is a trend in younger respondents reporting 
higher life satisfaction than older individuals, but this is not a well-defined development (Blanchflower, D.G. \& Oswald, A., 2004). Meanwhile, life-evaluation surveys from both LMIC and high income countries have found a reoccurring U-shaped pattern (Hayo, B., \& Seifert, W., 2003): satisfaction begins high in adolescence and thereafter declines consistently, reaching a minimum in middle-age (between 40 and 50), and then consistently rises again. This $U$-shape is more pronounced when controlling for income, marital status, health and employment status, reinforcing the fact that it is not only higher income or greater stability that explains the increased happiness perceived after the mid-life point.

Many studies have shown a strong correlation to exist between marital status of men and women and perceived well-being, notably Helliwell (2003) who found those reported as married were more likely to report being happiest on a spectrum scale, or report higher life satisfaction, followed by the classification group 'living as married'. Moreover, the single greatest depressant of reported happiness was the variable 'separated', closely followed by 'widowed', which reinforces marital status as a significant aspect of U.S. and UK populations' well-being in the last quarter century (Blanchflower et al., 2004).

Popular studies in the last decade have suggested that marriage can contribute more so to the positive well-being of men compared with women, however literature is currently mixed on this front, and this claim was unsupported by a 3 year World Values Survey review by Helliwell et al (2003). 
The total reported years of education often correlates positively with life satisfaction. However this correlation can vary from country to country as well as between cultures of the same country. Some studies have found that effects of different levels of education on well-being are small and insignificant (Helliwell et al. 2003), though the studies that found weak correlations of this nature typically collected data based on ages at which full-time education was finished, a limitation primarily due to survey design. Although the traditional economist perspective disagrees, educational attainment can act independently on well-being, not only as a proxy for income earnings. An analysis from Blanchflower et al. (2004) reveals that it is not earnings directly which has the strong observed effect on well-being, but rather education represents its own independent effect on well-being, apart from income.

\subsubsection{Gender disparities in well-being}

Though improvements in overall well-being are documented around the globe, marked inequalities by gender remain. Gender differences in both objective achievements and individual's subjective assessments of what they can do or be persist.

Gender disparities in well-being can be seen within each of the commonly acknowledged determinants of subjective well-being, such as education. For example, in rural India a strong gender bias has been found where the proportion of boys to girls surveyed as being 'in-school' increases at each grade level until senior secondary level, where all students in a recorded as boys (White, S., \& Jha, S., 2014). This trend is seen in many other low-income populations, resulting in females being less likely to receive formal education or training for income 
earnings. White \& Jha (2014) also found the major difference in overall mean scores of wellbeing in this rural Indian population to be by gender, with men reporting higher well-being. This contrasts with the general trend seen in more advanced countries, with females reporting higher satisfaction and happiness than their male counterparts.

When comparing men and women's life satisfaction over time, this trend diminishes, as women's well-being ratings do not increase as consistently as those of men (Blanchflower, 2008). Where women report higher life satisfaction than men, all other factors equal, their rates of mental illness are also higher, with women reporting more psychological stress (NolenHoeksema et al., 1999).

Interestingly, it has been found in US college populations that gender has no significant effect on any well-being measures, in both affective happiness and life-evaluative measures (Larsen et al. 1985).

\subsection{Food security and well-being}

Studies using cross-sectional and longitudinal approaches have reinforced the fact that household food insecurity is associated with multiple non-nutritional outcomes throughout the life-cycle (Nanama, S., Frongillo, E.A. 2012). Nanama \& Frongillo (2012), as well as other studies have led to the conceptualization that food security is strongly correlated to well-being, with many pathways involving social and psychological conditions. 
Based on previous research explained in section 2.1.1, specific social and psychological experiences are related to food insecurity. Often including coping strategies, these behaviors and experiences can be indicative of a specific level of severity of food insecurity. The most common social and psychological consequences associated with food insecurity were concerns, worries, and anxiety about food, often foretelling a mild or commencing state of food insecurity.

Additionally, alienation, social deprivation, as well as altered household cohesion are common reports from food insecure households and individuals (National Research Council, 2006). Alienation is expressed through feelings of shame, especially by the heads of household. This feeling often occurs when the household runs out of food and must rely on socially unacceptable ways of accessing food, such as borrowing food or asking others for food. These actions reveal the individual or household's food insecurity to others, and expose them to judgment about their ability to provide for themselves and dependents. The fear of criticism and alienation can shape decisions on how to manage food and cope with food insecurity, a sensitivity expected in small, rural or community-focused environments.

However, within developing countries' urban or semi-urban contexts, similar findings in social and psychological consequences of food insecurity were confirmed in South Africa (Lemke et al, 2003), Latin America (Moreno-Black et al, 2005) and Asia (Piaseu et al, 2004). These consequences appear to be universally experienced, and future food insecurity analysts are 
increasingly encouraged to include measurement of the well-being consequences that are closely linked to food insecurity.

\section{Chapter 3: General methodology}

\subsection{Research design}

This study is quantitative in nature, and uses a cross-sectional survey design. Data were collected at one point in time and were thereafter used to describe characteristics of the populations polled.

\subsection{Research context}

This study was conducted through a collaboration between McGill University's Institute for Global Food Security and the Voices of the Hungry (VoH) team at the Food and Agriculture Organization of the United Nations (FAO).

In 2012, FAO launched the $\mathrm{VoH}$ project, an innovative approach to developing a measure of the severity of food insecurity as experienced by individuals or households. The VoH project developed the Food Insecurity Experience Scale (FIES) and aims to establish it as a new global standard for measuring food insecurity experience that is valid, endorsed at the international level, and used for global and country monitoring.

To accomplish these goals, the FIES was incorporated into the 2014 Gallup World Poll (GWP), a branch of Gallup, Inc. who has been conducting nationally representative surveys annually in 
more than 150 countries since 2005 . This vehicle for data collection has enabled FAO to collect cross-culturally comparable information and provide country-level estimates of food insecurity severity. This marks the first nationally representative data on the 'food access' dimension of food security, at the individual level, on an annual basis and for a large number $(+150)$ of countries. A major advantage of measuring food insecurity at the individual level is that results can be meaningfully disaggregated by gender, so that different and comparable measures of the prevalence of food security among women and men can be calculated.

\subsubsection{Gallup World Poll}

Since Gallup created their World Poll (GWP) in 2005, surveys in more than 150 countries have assessed $99 \%$ of the world's adult population annually (Gallup, 2015).

The GWP uses a standard set of core questions that have been translated into the major languages of the respective country, with supplemental questions added to the core list in many countries. Such supplemental questions may include perceptions of youth development, community services, optimism, or certain current events, for example political outcomes, or natural disaster response.

Gallup is entirely responsible for the management, design, and control of Gallup Worldwide Research and their mission is to provide information in an objective, reliable and scientifically grounded manner. Gallup is not associated with any political orientation, party, or advocacy group. 
The FIES was incorporated into the GWP questionnaire in 2014, allowing FAO to collect crossculturally comparable information from individual respondents at a relatively low cost, and provide country-level estimates of food insecurity severity.

Because Gallup focuses on public opinion items and subjective assessments, and because the full global datasets they collect are not accessible without license or subscription, the validity of the GWP data is sometimes raised as an issue of concern. However, over the past years the validity of the data has been repeatedly assessed and the data is frequently used for crosscountry comparisons and trend analyses (Holmqvist, G. \& Natali L., 2014).

Numerous multilateral agencies use the GWP to produce international statistics. OECD uses World Poll data for its "Better Life Index" (OECD, 2014), and the World Bank for its Financial Inclusion Index (World Bank, 2014). FAO now joins this group by using the GWP for the FIES inclusion. The GWP methodology and data have been assessed by these organizations, and have been judged sufficient to produce statistics for cross-country comparisons (Holmqvist, G. \& Natali L., 2014). Among various other established academics, Angus Deaton has used the World Poll for international research for many years, going so far as to propose the World Poll as an alternative and compliment to regular income and poverty data (Deaton, A., 2010).

\subsubsection{The Food Insecurity Experience Scale}


The FIES is a measure of food insecurity at the individual or household level (see Appendix A). The decision to collect individual-level data in 2014 was based on the GWP methodology, which is historically a survey of individuals. However, the FIES can be easily applied at the household level with minor adaptations.

The FIES consists of eight questions that refer to the experiences of the individual respondent, or if household adaptations are used, of the respondent's household as a whole. The questions relate to self-reported food-related behaviors and experiences associated with increasing difficulties in accessing food due to resource constraints. The set of questions reflect a scale based on the well-grounded construct of the experience of food insecurity composed of three domains previously discussed in Chapter 2: uncertainty/anxiety, changes in food quality, and changes in food quantity. All eight questions are worded to be as concise and universally relevant as possible (Ballard et al., 2013). Since the scale is administered in approximately 150 countries, an important note on methodology refers to the efforts toward ensuring that the questions, as formulated in the language of administration, faithfully capture the concepts underlying the food insecurity scale.

In-depth linguistic adaptations of the FIES questions were conducted in national languages of Angola, Ethiopia, Malawi, and Niger following a common methodology, and the resulting versions were pilot tested in these countries in 2013. These studies provided invaluable information regarding phrases and concepts which require more careful adaptation, but also reassured FAO with respect to the robustness of the questions and the standard translation 
process employed by Gallup to translate all of the World Poll questions into local languages (Voices of the Hungry, 2015). Since it is not feasible to conduct in-depth adaptation work in every country and language within the logistical constraints of the GWP, lessons learned from the pilot studies were incorporated into an Explanatory Document to guide translation efforts and enumerator training, beginning with the 2014 data collection year.

The FIES allows for classification of individuals into varying severities of food insecurity. For the purposes of this study, respondents were categorized as "food secure" or "food insecure", based on the individual's sum of affirmatively answered (raw score) FIES questions. Those who respond "no" to all eight FIES questions (rather, those who have a raw score of zero), are classified as "food secure". Those who respond "yes" to 1-8 FIES questions (those who have a raw score of 1-8), are classified as "food insecure". This dichotomous categorization was adapted in collaboration with the $\mathrm{VoH}$ team, and in lieu of established global thresholds at publication time.

\subsubsection{Using Rasch modeling and Item Response Theory}

The FIES is a psychometric scale similar to other widely accepted scales designed to measure unobservable traits, such as aptitude or intelligence, personality conditions, and depression. Comparability of results across countries has been achieved through the use of statistical techniques borrowed from the toolkit of Item Response Theory (IRT) models, commonly used in the educational and psychological testing fields (Brunelli et al., 2014). 
The FIES was constructed using the One Parameter Logistics Model (or Rasch Model) based on IRT. When the model is applied to food insecurity measurement, the probability that a respondent with food insecurity responds positively to a scale item characterized by severity level can be modeled as a logistic function of the distance between these two aspects (Brunelli et al., 2014). This provides a theoretical base and a set of statistical tools that can assess the suitability of a set of questions for constructing a scale, and then comparing the performance of the scale in various populations and survey contexts (Nord, M., 2014). The reason IRT or Rasch modeling is a preferred theoretical basis for the FIES is that the model can be used to assess the location of a respondent along a continuum of the severity of lack of access to food, based on responses from multiple dichotomous (yes/ no) items (Ballard et al., 2013).

An important assumption of the Rasch model is that items are conditionally independent, that is, all correlations among questions result from their common association with the latent trait (Nord, M., 2014). The term 'latent trait' refers to an underlying phenomena or construct which cannot be directly observed (in this study, food security), but the extent of which can be inferred from indirect, observable indicators (Ballard et al, 2013).

Investigations were conducted by Brunelli et al. (2014) into how the FIES perform within the Rasch model, based on a 2013 data set from the pilot application in Malawi. Findings showed that the FIES performed well, with all fit statistics in the range of $0.8-1.2$, which is suggested by psychometric guidelines (Nord, 2014), to adequately meet the assumption of equal discrimination. This study by Brunelli also assessed the Rasch reliability, or the proportion of 
total variance accounted by the model, and found it to be 0.63 from the Malawi pilot data, which was considered acceptable. Of particular interest to the current study, Brunelli's 2014 analysis explored whether or not the items worked similarly between men and women, which is important to consider as significant discrepancies in item severity may imply the existence of a gender-based difference in the interpretation of that item. Only one item out of the eight item FIES scale was found to have statistically meaningful Wald test $p$-values that differed between genders, the question being, "..hungry but did not eat because there was not enough money or other resources for food," (Brunelli et al., 2014).

\subsubsection{Life satisfaction variable}

The life satisfaction variable used for this study was designed based on a question asked in the Core Questionnaire of the GWP:

Table 3.1 Life satisfaction variable, adapted from Gallup methodology (GWP, 2009)

\begin{tabular}{|l|l|}
\hline Question & Response Options \\
\hline Please imagine a ladder, with steps numbered from 0 at the & 00 Worst Possible \\
bottom to 10 at the top. The top of the ladder represents & 01 \\
the best possible life for you and the bottom of the ladder & 02 \\
represents the worst possible life for you. & 03 \\
& 04 \\
& 05 \\
& 06 \\
& 07 \\
& 08 \\
& 08 \\
\hline On which step of the ladder would you say you personally & 98 (DK) 99 (Refused) \\
feel you stand at this time, assuming that the higher the & \\
step the better you feel about your life, and the lower the & \\
step the worse you feel about it? Which step comes closest & \\
to the way you feel? & \\
\hline
\end{tabular}


Just your best guess, on which step do you think you will

stand in the future, say about five years from now?

Because of the nature of this research study, and reflecting consultation with Gallup Inc., only the first question (referencing the present) was considered for the current research analysis. The decision to omit the "future" component of the GWP question, listed in the third row of the figure above, was primarily based on the experience and recommendation of Gallup researchers that this question may closer measure such emotions as 'hope' or 'optimism', which is not within the scope of this study.

As of 2014, the GWP categorized individual responses to this life satisfaction question into three categories based on the single numerical score the respondent provided: "thriving" for responses between 7-10, "struggling" for 5-6, and "suffering" for 0-4. For the purposes of this study, and after consultation with Gallup Inc., a dichotomous variable was created by combining both "struggling" and "thriving" categories to create the "better off" group, leaving the original "suffering" group to become labeled "worse off".

\subsection{Sampling and survey methodology of the Gallup World Poll}

With few exceptions, all samples used by the GWP are probability-based and nationally representative of the resident population, beginning at age 15 (Gallup, 2009). Each country surveyed is covered entirely within sampling, including rural areas, with exception to areas 
where the safety of interviewing staff is threatened, scarcely populated islands in some countries, and areas that the interviewers can reach only by foot, animal, or small boat.

Telephone interviews are conducted in countries where telephone coverage represents at least $80 \%$ of the national population, and these interviews are typically 30 minutes in duration. In all other countries, face-to-face interviews are conducted over approximately one hour. In most countries where the GWP is administered, the survey is conducted one time each year, and fieldwork is generally completed within 2-4 weeks. The typical GWP annual survey includes at least 1,000 individual respondents, but in some large countries, such as China and Russia, sample sizes range from 2,000-5,000 individual respondents (Gallup, 2009). As the GWP is designed to be representative only at the national level, based on relatively small samples, further gender disaggregation within nations by age, ethnic group, or livelihood group is not often feasible. This is why the $\mathrm{VoH}$ is promoting inclusion of the FIES in largescale populationbased surveys in individual countries.

In countries where face-to-face interviews are conducted, the first stage of sampling is identifying 100-135 ultimate clusters, or Sampling Units, consisting of household clusters (Gallup, 2009). These Sampling Units are stratified by population size or geography. When information is available, sample selection is based on probabilities proportional to population size. If this population information is not available, simple random sampling is used. Each year, samples are drawn independent of any samples drawn from previous annual surveys. The second stage of sampling in these countries is devising a "random route procedure" to select 
sampled households, where the interviewer is provided a map of the sampled area. The third stage of sampling happens when respondents are randomly selected within the selected household, after the interviewer obtains a list of all eligible household members and their ages.

In countries where telephone interviews are conducted, random-digit-dial, or a nationally representative list of phone numbers is used. Random respondent selection is achieved by using either the latest birthday or Kish grid method.

\subsection{Data analysis}

Data were analyzed using IBM ${ }^{\circledast}$ SPSS $^{\circledast}$ version 21 . The Complex Sample module was used with the intention to improve the validity of statistical inferences by accounting for sample design in survey data analysis. Estimates were weighted using sampling weights calculated and provided by Gallup. A total of 142 countries with 139,412 respondents were included in the present study.

Independent variables used in this study are as follows (GWP, 2009):

Gender: the provided response to the GWP enumerator when the individual was asked to identify as a man or a woman. 
Marital status: the provided response to the GWP enumerator when the individual was asked to identify as single or never married, married, having a domestic partner, separated, divorced, or widowed.

Age: the provided response to the GWP enumerator when the individual was asked to provide their age in numerical value. Only those household members aged 15 or older were included in each country sample.

Education: Countries have unique ways of classifying education levels, and these classifications need to be preserved during data collection for weighting purposes. However, to make comparisons across countries by educational attainment, consistent categories also needed to be created. All education descriptions were placed within three categories by GWP: elementary (received up to eight years of basic education or less), secondary (completed 9-15 years of education), and tertiary (completed more than 15 years of education, and/ or received a fouryear college degree). All responses regarding education are coded into their relevant category for global comparison.

Income: To calculate income, respondents are asked to report their household income in local currency. Those respondents who have difficulty answering the question are presented a set of ranges in local currency and are asked which group they fall into. Income variables are created by converting local currency to International Dollars (ID) using purchasing power parity (PPP) ratios. Annual household income in international dollars (ID) is calculated using the World 
Bank's PPP private consumption conversion factor. Respondents answering the household income question with continuous data values are divided by the PPP ratio to obtain income measures in ID. Missing values of income are imputed using multiple imputation. To determine per capita income (which was used for current study), the imputed Household Income is divided by the Imputed Household Headcount. All income is reported in International Dollars.

Household size: calculated using the number of residents aged 15 and older in household and the number of children younger than 15. Missing values are imputed from annual data using multiple imputation.

Country: the provided response to the GWP enumerator when the individual was asked to report in which country they currently reside. Countries included in the present study are: Afghanistan, Albania, Algeria, Angola, Argentina, Armenia, Australia, Austria, Bahrain, Bangladesh, Belarus, Belgium, Belize, Benin, Bolivia, Bosnia Herzegovina, Botswana, Brazil, Bulgaria, Burkina Faso, Burundi, Cambodia, Cameroon, Canada, Chad, Chile, Colombia, Congo Brazzaville, Congo Kinshasa, Costa Rica, Croatia, Cyprus, Czech Republic, Denmark, Dominican Republic, Ecuador, Egypt, El Salvador, Estonia, Ethiopia, Finland, France, Gabon, Georgia, Germany, Ghana, Greece, Guatemala, Guinea, Haiti, Honduras, Hong Kong, Hungary, India, Indonesia, Iran, Iraq, Ireland, Israel, Italy, Ivory Coast, Jamaica, Japan, Jordan, Kazakhstan, Kenya, Kosovo, Kyrgyzstan, Latvia, Lebanon, Liberia, Lithuania, Luxembourg, Macedonia, Madagascar, Malawi, Malaysia, Mali, Malta, Mauritania, Mauritius, Mexico, Moldova, Mongolia, Montenegro, Myanmar, Namibia, Nepal, Netherlands, New Zealand, Nicaragua, 
Niger, Nigeria, Northern Cyprus, Norway, Pakistan, Palestine, Panama, Paraguay, Peru, Philippines, Poland, Portugal, Puerto Rico, Romania, Russia, Rwanda, Saudi Arabia, Senegal, Serbia, Sierra Leone, Singapore, Slovakia, Slovenia, Somalia, South Africa, South Korea, South Sudan, Spain, Sri Lanka, Sudan, Sweden, Switzerland, Taiwan, Tajikistan, Tanzania, Thailand, Togo, Tunisia, Turkey, Uganda, Ukraine, United Arab Emirates, United Kingdom, United States, Uruguay, Uzbekistan, Venezuela, Vietnam, Yemen, Zambia, and Zimbabwe.

\subsubsection{Descriptive statistics and bivariate analyses}

Descriptive statistics were carried out to explore the distribution of responses for all variables previously listed. Means, confidence intervals, and ranges were calculated for continuous variables such as income, age, and household size, while frequency distributions were generated for all categorical variables (gender, food insecurity status, life satisfaction, education level, and marital status).

Bivariate analyses were performed using complex sample cross-tabulation, for each pair of predictor and outcome variables, to explore the possible correlations and to determine their strength and direction. Statistical significance was set at $p<0.05$ for all tests. These predictor variables were then further examined within multivariable models.

\subsubsection{Multiple logistic regression models}

Two multivariable logistic regression models were created. Model \#1 was created to explore the effect of gender on the likelihood that participants suffer from food insecurity. This model 
allows identifying if women have higher odds of being food insecure than men, as primarily hypothesized. Model \#2 was created to ascertain whether gender and food insecurity affect the likelihood of participants to report lower life satisfaction. A new variable was created that combined food security status and gender to form mutually exclusive categories, including food secure men, food insecure men, food secure women, and food insecure women. The reference category, or rather, the group with the highest reported life satisfaction, was food secure women. This model is expected to allow the verification of the secondary hypothesis, if food secure men will report higher life satisfaction than food insecure males, as well as food secure and food insecure women.

Both models were adjusted for age, marital status, income, education level and country of residence. These variables were chosen for their theoretical influence on food security from recent and relevant literature (Melgar-Quinonez et al., 2008; Zakari et al., 2014).

The dependent variable for multiple logistic regression model \#1 was food insecurity, which refers to the individual's food security status as classified by the categorization of each respondent's FIES raw score, or the number of affirmatively answered FIES questions. Food insecurity status was classified into 2 categories: food secure raw score was 0 , food insecure if raw score was 1-8. One version of this model did not control for further independent variables, hence the previously discussed bivariate analysis providing an unadjusted OR for the likelihood of women being food insecure, versus men. The multivariate version of this model controlled for multiple independent variables, listed in chapter 3.4 . 
The dependent variable used for multiple logistic regression model \#2 was life satisfaction, which refers to the individual respondent's perceived life satisfaction as classified by the life satisfaction question adapted by GWP. A single numerical response between 0-4 classified the respondent as "worse off", while a response between 5-10, classified the respondent as "better off". GWP currently uses three categories for their life satisfaction rating: the "worse off" category adopted for this study uses the same 0-4 cutoff for their "suffering" category, while the "better off" category constructed for this study combines the higher two categories. This dichotomized variable was constructed based on empirical relationships established in research conducted since 2006, and Gallup's judgment and experience with the measure for application in the current study. The percentage of respondents that fall into each category correlates with other country-level characteristics, providing evidence of the construct validity of the categories (Gallup, 2009).

\subsection{Ethical considerations}

The present research was based on secondary data collected by Gallup Worldwide Research, a division of Gallup, Inc., as part of the 2014 Gallup ${ }^{\circledR}$ World Poll. Gallup states that it is "committed to the principle that accurately collecting and disseminating the opinions and aspirations of people around the globe is vital to understanding our world. Gallup's mission is to provide information in an objective, reliable, and scientifically grounded manner." Gallup is not associated with any political group or orientation, and only accepts non-partisan clients. It upholds the confidentiality of both its clients and all respondents surveyed. 
Gallup maintains a compliance and ethics program comprised of written standards of conduct and policies and procedures, designation of a Regulatory Compliance Officer, and investigation and remediation of systemic problems. Additionally, Gallup's Board of Directors exercises reasonable oversight of the implementation and effectiveness of the program (Gallup, 2015).

Within Gallup's Respondent Confidentiality clause, they state that they do not provide third parties - including clients or members of the public - with information that allows them to connect respondents' answers to survey questions with identifying information (including identification numbers, names, addresses, telephone numbers) with only one exception. This only exception is the case in which respondents are asked whether they would be willing to allow Gallup to release their answers to the client, and to identify them as the source of that information. Furthermore, Gallup does not use information collected in survey interviews as the basis for drawing prescreened samples of respondents for independent survey projects, with only one exception. This exception is the case in which respondents are asked whether they would be willing to be called back for purposes of a subsequent interview.

\section{Chapter 4: Manuscript}

\section{Gender disparities in perceived life satisfaction within food insecure populations} Elizabeth A. Graham, ${ }^{1}$ Terri Ballard, ${ }^{2}$ Diana Dallmann, ${ }^{3}$ Hugo Melgar-Quiñonez. ${ }^{3}$

1. School of Dietetics and Human Nutrition, McGill University, Montreal, Canada

2. Food and Agriculture Organization of the United Nations (FAO), Rome, Italy

3. McGill Institute for Global Food Security, Ste-Anne-de-Bellevue, QC, Canada

To be submitted to Journal of Public Health Nutrition. 


\subsection{Abstract}

Food insecurity plagues individuals worldwide, even in those countries with a surplus in food supplies. Numerous studies show females are over-represented among the global food insecure population; a 2009 estimate reported $60 \%$ of undernourished people worldwide are women or girls. Little research has examined the way food insecure affects men and women's perception of their own life satisfaction. By asking individuals whether they are satisfied with their lives, underlying crises or hidden strengths can be understood. The primary objective of this study is to analyse whether gender is a global risk factor for experiencing food insecurity. The secondary objective is to explore the relationship between food insecurity and reported life satisfaction, and how that relationship may be more pronounced by gender. Through a collaboration with the Food and Agriculture Organization of the UN, this study utilized data collected through the 2014 Gallup World Poll ${ }^{\circledR}$ which included the Food Insecurity Experience Scale. The GWP is a nationally representative survey conducted annually in over 150 countries. Responses to the FIES (8 questions) comprised the food insecurity variable, with 0 affirmative responses denoting food security, and 1-8 affirmative responses denoting food insecurity. A single well-being question (adapted from Hadley Cantril's Self-Anchoring Striving Scale) comprised the life satisfaction variable, with possible answers ranged 0-10. Responses 4 or lower denoted "worse off" or low life satisfaction, versus 5-10 categorized "better off". Analysis was conducted using IBM SPSS Statistics 22, using the complex sample module. Descriptive and bivariate analyses were employed to understand which independent variables are related to life satisfaction, considering intensity and direction. Two multivariate logistic regression models were created; one to examine the likelihood of being food insecure based on gender, and another to examine the likelihood of reporting higher life satisfaction based on food security status and gender. Both models adjusted for age, marital status, income, education level, and country of residence. Cross-sectional data from 142 countries shows that, globally, $47.7 \%$ of population was food insecure, with nearly a third of the total sample (32.4\%) categorized as "worse off" for life satisfaction. Women had higher odds for food insecurity than men in both unadjusted (OR: 1.14, 95\% Cl=1.11-1.16), as well as adjusted models (OR: 1.04, 95\% Cl=1.01-1.07). Food insecurity and life satisfaction were found significantly correlated, with those who were food insecure having significantly higher odds of perceiving low life satisfaction (OR: $3.25,95 \% \mathrm{Cl}=$ 3.14-3.36). Furthermore, this analysis revealed for the first time on a global scale, that men are consistently less likely to report higher life satisfaction than their female counterparts (OR: $0.83,95 \% \mathrm{Cl}=0.81-0.86$ ) when controlling for food insecurity, among other variables. Adjusting for independent variables, food insecure men, food insecure women, and food secure men had, respectively, 3.89, 3.31, and 1.24 times higher odds to report "worse off" life satisfaction when compared to food secure women. This research provides evidence of differing reports of overall life satisfaction between men and women who experience the same food (in)security status. This reinforces the need for re-structuring typical food-security programs (and other public services) and to measure individual well-being consequences which often precede physical consequences of food insecurity. This study supports implementing well-being and food insecurity assessments in unison, to understand how food insecurity in specific economic and social contexts varies. Continued research is necessary to explore why life satisfaction is viewed differently by men and women, what the consequences are then for those food insecure 
populations and what implications exist for policies aimed at improving food security. Keywords: food security, gender, life satisfaction, subjective well-being, experience-based scale

\subsection{Introduction}

In 1996 the World Food Summit established the definition of food security as, "when all people, at all times, have physical, social and economic access to sufficient, safe and nutritious food which meets their dietary needs and food preferences for an active and healthy life," (Food and Agriculture Organization of the United Nations, 1996). Since then, the demand for food security measures that reflect the complex dimensions of food availability, access, utilization, and stability has continued, and unfulfilled to date (Cafiero et al., 2014). There is a need for food insecurity measures that go deeper than national level, which can provide realistic and nuanced information currently unattainable through national food balance sheets and other macro-level assessments. To this end, population surveys can better reflect direct evaluations of a household or individual's access to food. Experience-based food insecurity scales emerged in recent decades to fill this need and to capture a broader concept of food insecurity.

The Food Insecurity Experience Scale (FIES) is comprised of questions that assess behavioral domains known to exist at differing levels of food insecurity (Voices of the Hungry, 2014), and is based on similar experience-based scales such as the U.S. Household Food Security Survey Module (USDA, 2014), the Household Food Insecurity Access Scale (Coates et al., 2007), and the harmonized Latin American and Caribbean Food Security Scale (Pérez-Escamilla et al., 2007).

Research measuring perceived well-being has used numerous measures of subjective wellbeing in the last decades, most falling between two distinct groups: life evaluations (life 
satisfaction measures) and acute emotional reports. It has been noted in most high-income countries that women report higher in both satisfaction and happiness measures than men (Helliwell et al., 2012). To date, the Gallup World Poll ${ }^{\circledR}$ (GWP) provides the broadest country coverage of well-being measurement, administering an individual-level adapted version of the Cantril Self Anchoring-Striving scale, a commonly used well-being indicator established in the 1970's for public polling.

In 2009 it was reported that $60 \%$ of the global undernourished population was comprised of women or girls (Asian Development Bank, 2013), which highlights the consistent overrepresentation of women in the malnourished population. However, no research has measured prevalence of food insecurity at the individual level, using a comparable methodology across developing and developed countries. The need for accurate measurement of food insecurity and well-being is evident, and requires a change in approach to how men and women are represented within and across these spectrums.

The purpose of this study is to explore how gender may be a global risk factor for food insecurity, as well as investigate the potential link between food security and perceived life satisfaction, and analyse if gender disparity exists within this relationship. 


\subsection{Methodology}

This study is quantitative in nature, and uses a cross-sectional survey design. Data were collected at one point in time and were thereafter used to describe characteristics of the populations polled.

\subsubsection{Context}

This study was conducted via collaboration between McGill University's Institute for Global Food Security and the Food and Agriculture Organization of the United Nations (FAO).

FAO launched their Voices of the Hungry ( $\mathrm{VOH}$ ) project in 2012, which is an innovative approach to developing a measure of the severity of food insecurity as experienced by individuals or households worldwide. The $\mathrm{VoH}$ project developed the FIES and aims to establish this scale as the new global standard for measuring food insecurity experience that is valid, endorsed at the international level, and used for global and country monitoring (Voices of the Hungry, 2015). In 2014 the FIES was incorporated into the Gallup World Poll (GWP), a branch of Gallup, Inc. which has been conducting nationally representative surveys annually in more than 150 countries since 2006 .

The FIES measures food insecurity at the individual or household level. The choice to collect individual-level data in 2014 was based on the Gallup World Poll ${ }^{\circledR}$ methodology, which is a survey of individuals. The FIES is a psychometric scale similar to other widely accepted psychometric scales designed to measure unobservable traits, such as intelligence, personality 
conditions, and depression. Comparability of results across countries is achieved by applying the One Parameter Logistics Model, often referred to as Rasch Model, which is a statistical technique from the toolkit of Item Response Theory (IRT) models. These psychometric scales are commonly used in the educational and psychological research fields (Cafiero et al., 2014).

The FIES is the global version of the first eight questions of the ELCSA, administered at the individual level. An important pre-requisite towards developing a tool measuring severity of food insecurity in a comparable way across multiple cultures is careful linguistic adaptation, which was undertaken in 2013 as part of a 4-country FIES pilot study using the FIES. This global tool is based on the premise that universal dimensions of experienced food insecurity (Swindale, A. \& Bilinsky, P., 2006), as well as evidence showing the cross-cultural validity and applicability of measures that preceded the FIES (Voices of the Hungry, 2015), support the use of a standardized measure that enables international comparisons.

\subsubsection{Sampling and survey methodology}

Since Gallup created their World Poll in 2005, surveys in more than 150 countries annually have assessed $99 \%$ of the world's adult population (Gallup, 2015).

With few exceptions, all samples used by the GWP are probability-based and nationally representative of the resident population, beginning at age 15. Each country surveyed is covered entirely within sampling, including rural areas, with exception to areas where the safety of interviewing staff is threatened (Gallup, 2009). 
Telephone interviews are conducted in countries where telephone coverage represents at least $80 \%$ of the national population. In these countries, random-digit-dial, or a nationally representative list of phone numbers is used. Random respondent selection is achieved by using either the latest birthday, or Kish grid method. Telephone interviews are about 30 minutes in duration.

In countries with less than $80 \%$ phone coverage, face-to-face interviews are administered, which run for approximately one hour each. The first stage of sampling in these countries is to identify 100-135 ultimate clusters, or Sampling Units, consisting of household clusters. These Sampling Units were stratified by population size or geography. Where available, sample selection is based on probabilities proportional to population size. If population information is not available, simple random sampling is used.

Each year, samples are drawn independent of any samples from previous year's surveys. The second stage of sampling in these countries is to devise a "random route procedure" to select sampled households, where the interviewer is provided a map of the sampled area. The third stage of sampling happened when respondents are randomly selected within the selected household, after the interviewer obtains a list of all eligible household members and their ages.

The typical GWP annual survey includes at least 1,000 individual respondents per country, though in some large countries, such as Russia and India, sample sizes range from 2,000-5,000. 


\subsubsection{Variables created}

The food insecurity variable used for this study was constructed from the eight-item FIES module. Each question asks the individual to report on specific food-related behaviors and experiences, scanning a spectrum of difficulties in accessing food due to resource constraints. The set of questions reflect a well-grounded spectrum construct of the food insecurity experience that comprises three domains: uncertainty/anxiety, changes in food quality, and changes in food quantity (Voices of the Hungry, 2015).

For the purposes of this study, individual respondents were categorized as "food secure" if all questions were answered "no". Respondents were categorized as "food insecure" if they answered "yes" to 1-8 of the FIES questions. These categories were adapted in collaboration with the $\mathrm{VoH}$ team at FAO, and in lieu of published global thresholds at publication time.

The life satisfaction variable used for this study was a single item asked in the GWP core questionnaire, which reads, "Please imagine a ladder with steps numbered from zero at the bottom to ten at the top. Suppose we say that the top of the ladder represents the best possible life for you, and the bottom of the ladder represents the worst possible life for you. On which step of the ladder would you say you personally feel you stand at this time? (Gallup, 2009)" 
The categories currently used by GWP were constructed based on empirical relationships established during Gallup's research experience with the measure. The percentage of respondents that fall into each category correlates with other country-level characteristics of well-being, providing evidence of the construct validity of the categories (Gallup, 2009).

The GWP currently categorizes individuals as "thriving" if response ranges between 7-10, "struggling" for 5-6, and "suffering" for 0-4. For the purposes of this study, the "struggling" and "thriving" categories were combined to create the "better off" group, leaving the original "suffering" group to become labeled "worse off", based on the single numerical score the respondent provided.

\subsubsection{Analysis}

Descriptive analyses were carried out to explore the distribution of responses for all variables previously listed. Means, confidence intervals, and ranges were calculated for continuous variables such as income, age, and household size, while frequency distributions were generated for all categorical variables (gender, food insecurity status, life satisfaction, education level, and marital status).

Bivariate analyses were performed using complex sample cross-tabulation, for each pair of predictor and outcome variables, to explore the possible correlations and to determine their strength and direction. Statistical significance was set at $<0.05$ for all tests. These predictor variables were then further examined within multivariable models. 
Two multivariable logistic regression models were created. Model \#1 was created to explore the effect of gender on the likelihood that participants suffer from food insecurity. This model highlights if women have higher odds of being food insecure than men, as primarily hypothesized. Model \#2 was created to ascertain whether gender and food insecurity affect the likelihood of participants to report lower life satisfaction. A new variable was created that combined food security and gender to form mutually exclusive categories, including food secure men, food insecure men, food secure women, and food insecure women. The reference category, or rather, the group with the highest reported life satisfaction, was food secure women. This model allows the verification of the secondary hypothesis, if food secure men will report higher life satisfaction than food insecure males, as well as food secure and food insecure women.

Both models were adjusted for age, marital status, income, education level and country of residence. These variables were chosen for their theoretical influence on food security from recent and relevant literature.

The dependent variable for MLR model \#1 was food insecurity, which refers to the individual's food security status as classified by the categorization of each respondent's FIES raw score, or the number of affirmatively answered FIES questions. Food insecurity status was classified into 2 categories: food secure raw score was 0 , food insecure if raw score was $1-8$. One version of this model did not control for further independent variables, hence the previously discussed 
bivariate analysis providing an unadjusted OR for the likelihood of women being food insecure, versus men. The multivariate version of this model controlled for multiple independent variables, listed in chapter 3.4 .

The dependent variable used for MLR model \#2 was life satisfaction, which refers to the individual respondent's perceived life satisfaction as classified by the life satisfaction question adapted by GWP. A single numerical response between 0-4 classified the respondent as "worse off", while a response between 5-10, classified the respondent as "better off". GWP currently uses three categories for their life satisfaction rating: the "worse off" category adopted for this study uses the same 0-4 cutoff for their "suffering" category, while the "better off" category constructed for this study combines the higher two categories. This dichotomized variable was constructed based on empirical relationships established in research conducted since 2006, and Gallup's judgment and experience with the measure for application in the current study. The percentage of respondents that fall into each category correlates with other country-level characteristics, providing evidence of the construct validity of the categories (Gallup, 2009).

\subsection{Ethical considerations}

The present research was based on secondary data collected by Gallup Worldwide Research, a division of Gallup, Inc., as part of the 2014 Gallup $^{\circledR}$ World Poll. Gallup states that it is "committed to the principle that accurately collecting and disseminating the opinions and aspirations of people around the globe is vital to understanding our world. Gallup's mission is to provide information in an objective, reliable, and scientifically grounded manner." Gallup is 
not associated with any political group or orientation, and only accepts non-partisan clients. It upholds the confidentiality of both its clients and all respondents surveyed.

Gallup maintains a compliance and ethics program comprised of written standards of conduct and policies and procedures, designation of a Regulatory Compliance Officer, and investigation and remediation of systemic problems. Additionally, Gallup's Board of Directors exercises reasonable oversight of the implementation and effectiveness of the program.

Within Gallup's Respondent Confidentiality clause, they state that they do not provide third parties - including clients or members of the public - with information that allows them to connect respondents' answers to survey questions with identifying information (including identification numbers, names, addresses, telephone numbers) with only one exception. This only exception is the case in which respondents are asked whether they would be willing to allow Gallup to release their answers to the client, and to identify them as the source of that information. Furthermore, Gallup does not use information collected in survey interviews as the basis for drawing prescreened samples of respondents for independent survey projects, with only one exception. This exception is the case in which respondents are asked whether they would be willing to be called back for purposes of a subsequent interview.

\subsection{Results}

A total of 142 countries with 139,412 respondents were included in the present study. A summary of key descriptive findings can be found in Table 4.1. It was found that food insecurity 
affected $47.7 \%$ of the total population. In looking at each respondent's reported life satisfaction, $32.4 \%$ of the sample was categorized as being "worse off". Regarding education level, $39.7 \%$ of the sample reported completing elementary or less (8 or less total years of education). The average age of the respondent was 39.4 (95\% $\mathrm{Cl}: 39.3-39.5)$, while minding this sample pulled from household members aged 15 or older. The average annual income per respondent was 6,734.3 International Dollars (95\% $\mathrm{Cl}:$ 6,634.7-6,833.9).

Table 4.2 shows bivariate analyses of demographic characteristics by food insecurity, which illustrates that only $16.9 \%$ of food secure respondents reported low life satisfaction, while nearly half of the food insecure respondents (49.9\%) were categorized as "worse off". Further, education has a significant trend with food security: only $6 \%$ of those with tertiary education were found to be food insecure, versus $54.3 \%$ of elementary educated respondents. The average reported income (adjusted in International Dollars) for food secure respondents was 10,213.4 ID, versus 2,901.4 ID for food insecure. The food secure respondents were significantly older than the food insecure respondents, 40.8 versus 37.9 , respectively.

Table 4.3 shows bivariate analyses of characteristics by gender, illustrating a higher prevalence of food insecurity for women than men (49.2\% versus $46.1 \%)$. More men reported attaining some secondary $(49.9 \%)$ or completing a tertiary level education $(13.0 \%)$ than did women (45.6\% secondary, $12.0 \%$ tertiary education). Average weighted incomes were significantly different, 7,157.2 ID for men, and 6,329.5 for women, while average age was nearly equal 
between both genders. Nevertheless, significantly more women than men had life satisfaction responses that categorized them as "better off" (68.6\% versus $67.1 \%)$.

Table 4.4 demonstrates differences in these characteristics by life satisfaction. $58 \%$ of respondents with low life satisfaction, categorized as "worse off", reported only attaining an elementary level education or less, compared with $29.8 \%$ of the "better off" responders. The widest difference in life satisfaction within marital status was seen in the widowed group (4.9\% of "better off", versus $7.6 \%$ of "worse off"). The average per capita income for those categorized "better off" was 8,783 ID, versus 2,694 ID for those categorized "worse off".

The first logistic regression model, shown in Table 4.5, was found statistically significant, Wald $F(7)$ 1292, with $p<0.001$. The model explained 22.3\% (Nagelkerke R2) of the variance in food insecurity and correctly classified $68.8 \%$ of cases. Sensitivity was $69.6 \%$, specificity was $68.0 \%$, positive predictive value was $66.4 \%$ and negative predictive value was $71.1 \%$. All predictor variables were statistically significant. When adjusting for these predictor variables, women had 1.04 times higher odds to experience food insecurity than men (OR: $1.04,95 \% \mathrm{Cl}=1.01-1.07)$.

The second logistic regression model, shown in Table 4.6, was also found statistically significant, Wald $F(7)$ 1434, with $p<0.001$. The model explained 24.2\% (Nagelkerke R2) of the variance in life satisfaction and correctly classified $72.8 \%$ of cases. Sensitivity was $47.3 \%$, specificity was $85.1 \%$, positive predictive value was $60.6 \%$ and negative predictive value was $77.0 \%$. With the exception of marital status, all predictor variables were statistically significant. When adjusting 
for independent variables, food insecure men, food insecure women, and food secure men had, respectively, 3.89, 3.31, and 1.24 times higher odds to report "worse off" life satisfaction when compared to food secure women (Table 4.6). When no independent variables were adjusted for in the model, food insecure men, food insecure women, and food secure men had, respectively, 5.65, 5.07, and 1.18 times higher odds to report "worse off" life satisfaction when compared to food secure women.

\subsection{Discussion}

Progress in recent years to develop, refine, and implement individual level measures continue, yet are not mainstreamed in field of food security measurement to date (Brunelli et al., 2014). While the proportion of undernourished people globally decreased from $23.2 \%$ in $1990-1992$ to $14.9 \%$ in 2010-2012 (FAO, 2011), the exact number of food insecure individuals, and the extent to which they are affected, remains unspecified within countries.

It is essential to use reliable and validated measurements to estimate the extent of food insecurity at an individual level, which can provide realistic and nuanced information to more macro-level assessments. To date, there is no "gold standard" for measuring food insecurity (Coates et al., 2006), and so an array of measurement instruments are needed to account for the multiple dimensions.

One indicator selected to monitor the progress toward achieving the first MDG was the FAO Prevalence of Undernourishment (PoU). This is an estimate of the number of people who are 
likely not ingesting enough food to meet dietary energy needs, based on national estimates of total food energy available for human consumption, and distributions of energy requirements and consumption in the population (FAO, 2012). While the POU can be used to appropriately monitor national and regional trends in undernutrition estimates related to estimates of needs, it does not identify who the food insecure are, or where they live within countries, and thus is not a direct indicator of access to food at the household or individual level.

The second indicator used to monitor the first MDG was weight-for-age (measure of underweight) of children under five years of age. This anthropometric measure (along with height-for-age, measure of stunting) provides invaluable information regarding the nutritional status of children. However, similar to the POU, using anthropometric measures such as underweight or stunting is costly and requires a sophisticated level of data collection expertise, as they are a direct measure of malnutrition, rather than representing food insecurity.

As the nutrition transition has become increasingly evident in countries worldwide, comprising a decreasing prevalence of undernutrition and increasing rates of overweight among low income or less privileged groups, these measurement tools and preconceived assumptions regarding the association between poverty, hunger, and malnutrition are being re-evaluated (Monteiro, C.A., Conde, W.L. \& Popkin, B.M., 2004). Due to the complex relationship between food security and underweight, as well as overweight, the use of anthropometric measures as proxy indicators of household food security has been recently challenged in its appropriateness (Frongillo, E.A. 2003). 
During the 1990's, ethnographic research was conducted in rural New York State which revealed hunger to be a process characterized by initial worrying about having enough food, followed by dietary changes to make limited food resources last, and finally, decreased consumption of food in the household (Radimer, K.L., Olson, C.M., Greene, J.C., Campbell, C.C. \& Habicht, J.P. 1992). This evidence for conceptualizing the experience of hunger, based on research by Radimer and others, coincided with nations' increasing focus on unequal access to food and socio-cultural aspects of the experience of hunger (Sen A. 1981). This paved the way for experience-based food insecurity scales to be used, with comparable patterns found in U.S. elderly food insecure populations, as well as low-income families in Quebec, Canada (Hamelin, A.M. et al., 2002).

This study supports previously suggestion that the access component of food insecurity can be measured most accurately at the individual. Only through understanding who consumes what can we appreciate the impact of sociocultural and gender inequalities on people's ability to meet their dietary needs (Brown et al, 2008). Factors influencing individual-level food insecurity can include unhealthy environments, such as inadequate hygiene and sanitation. This situation can result in frequent illnesses and therefore compromise nutritional outcomes, despite sufficient food being available at the household or national level (Brown et al., 2008). Additional risk for food insecurity exists for infants and young children, whose mothers perform agricultural work and are often unable to feed their children as often as necessary to provide good nutrition, especially within peak agricultural seasons. 
Although nutritional standards, often denoted as dietary recommendations, are known for the nutritional needs of men, women, boys, and girls of different ages and physiological states (for example, pregnancy and lactation) these recommendations are not universally adhered to, often due to cultural practice and personal beliefs. For example, evidence from South East Asia shows that women of a household tend to eat after everyone else, and are less likely than men in the same household to consume preferred foods such as meats and fish, which are often the most nutrient-dense (Brown et al., 2008). It was also found by Brown et al. (2008) during times of crisis in low-income countries, women and girls are often forced to reduce their intake in favor of other household members, particularly men and boys, which can result in higher malnutrition rates among females in food insecure populations.

A study using datasets from the 2001-2008 National Health and Nutrition Examination Surveys (NHANES) shows intra-household differences in food security, consistent with the present study's findings: U.S. women were more likely to experience food insecurity than U.S. men of similar age in households with the same food insecurity and income (Nord, 2011). This finding supports the idea that the number of individuals in food insecure households should not be used to represent the number of food insecure people (Brunelli et al., 2014), and that individual-level food insecurity measures are necessary for exploring the true number and location of food insecure people. Similar analyses were conducted in adolescent populations in Southwestern Ethiopia (Hadley et al., 2007), where girls were more likely than boys to experiencing food insecurity in food insecure households. 
The ways in which women and girl's food security are affected external of the household can be described through their limited access to education and employment opportunities (Asian Development Bank, 2013), which can stunt their economic autonomy and weaken their bargaining position within the family or community. Women's weaker decision-making can translate into little or no voice in household decisions, observing differential feeding and caregiving which favor boys and men, experiencing food and nutrition insecurity, and potentially lower health and nutrition outcomes (Asian Development Bank, 2013).

Furthermore, women and girls worldwide face constraints related to food production which are often embedded in social norms and practices and possibly enforced through national legislation (Doss, 2011). Some laws, such as those governing access to land, include inequitable and exclusionary practices. Doss (2011) found that these unequal rights can negatively affect women's food production, as they are less likely to own land and usually enjoy only 'use' rights, mediated through a male relative. These limitations can affect not only the woman's food security and nutrition, but all household members dependent on that woman.

Similar to food security, well-being has been researched through various sectors. It is generally agreed that a wide range of functions and capabilities will determine if people are able to lead a good life, with current research including economic status, physical and mental health, family circumstances, and human and political rights measures, among others (Deaton, A. 2008). The OECD provides a generous definition of subjective well-being for their 2013 Guidelines as, 
"Good mental states, including all of the various evaluations, positive and negative, that people make of their lives, and the affective reactions of people to their experiences."

The broad and all-encompassing nature of OECD's definition, like many other leading researchers' definitions, creates an illusion of well-being as an eternally vague concept. However, there is conclusive agreement that two unique aspects comprise subjective wellbeing (Dolan and White, 2007; ONS, 2011): life evaluations and measures of affect. Life evaluation is the element of subjective well-being that is assessed in this current study.

Life evaluation as well as daily affect measures of subjective well-being provide an alternative yardstick of progress that is grounded in people's experiences, differing from other more conventional metrics that focus on access to resources (Helliwell et al., 2012). This study argues that this disparity should be viewed desirably, as it offers nuanced evidence that is grounded in people's experiences and judgments, a part from the economic and social indicators typically employed.

An important example of this is the case of the GDP growth and the "Arab Spring", a revolutionary wave of demonstrations and protests in the Arab world against oppressive rule from 2010- 2012. Real GDP per capita increased 7\% in Tunisia from 2008-2010, however the proportion of the population indicating a high level of satisfaction with their life as a whole fell from $24 \%$ to $14 \%$ over the same time period. Egypt showed a similar pattern from $2005-2010$, with a real gain in GDP per capita around 34\%, and a decline in the share of respondents 
reporting a high level of life satisfaction by almost half (OECD, 2013). For policy-makers, subjective well-being measures are valuable indicators that can alert them to issues that other economic indicators might fail to identify, which can save community infrastructure and human lives.

Though improvements in overall well-being variables are documented around the globe, marked inequalities by gender remain. An example of gender disparities in educational attainment can be seen in White et al.'s paper from India, where the proportion of boys to girls surveyed as being 'in-school' increases at each grade level until senior secondary level, where all students were recorded as boys (White, S., \& Jha, S., 2014). This trend is seen in many other low-income nations, resulting in females being less likely to receive formal education, while at the same time less likely to report a higher well-being. The same study in India found a major difference in overall mean scores of well-being by gender, with males reporting higher wellbeing. This is contrary to the trend is seen in most other high and low-income countries, where females are more likely to report higher satisfaction and happiness than their male counterparts (Helliwell et al., 2012).

Looking at well-being rates of populations over time, women's well-being ratings do not increase as drastically as those of men (Blanchflower, 2008). As of the late 1990's, women reported higher life satisfaction than men, all other factors equal, yet their rates of mental illness were also higher, judged based on women reporting more psychological stress (NolenHoeksema, S., \& Rusting, C. L., 1999). 
Numerous international public opinion surveys such as the GWP (Gallup, 2009), The World Values Survey (WVS, 2015), the European Values Survey (EVS, 2014) and the European Social Survey (ESS, 2015), have adapted a variation of the Cantril Self-Anchoring Striving Scale. As of 2010, the Cantril ladder was considered a serious contender for the best tool for measuring the degree to which individuals view themselves as achieving their overall goals, both material and other (Kahneman et al., 2010).

The Cantril Ladder represents a self-perceiving well-being measure that has been used in both low and high-income nations for more than four decades. Hadley Cantril and his assistants conducted the Pattern of Human Concerns study based on data from 18 countries, between 1957- 1963 in partnership with the Institute for International Social Research and Princeton University (Cantril, H., 1977). The Self-Anchoring Striving Scale was designed as an open-ended scale, asking the respondent to visualize a ladder with 10 rungs. The respondent was then asked to define his or her wishes and hopes, symbolizing the top rung, and then worries or fears, placed on the bottom rung, creating a self-defined spectrum (Cantril, H., 1977).

When considering validity, we must note that subjective well-being measures have been correlated with objective measures of well-being such as facial expressions, brain-wave patterns and cortisol measures at the individual level, as well as community and national suicide patterns. This is helpful when research concerns interpersonal and intercultural differences in how people may use words or behaviors relating to well-being, and some 
researchers argue these correlations are necessary before considering subjective well-being measures as serious indicators. Yet the coincidental movements of physical attributes, reasoned in the World Happiness Report (Helliwell et al., 2012) are of less consequence compared to the subjective measure of well-being, as this subjective perception is the primary element to be described, while certain patterns of electrical activity in the brain only became established as measures of well-being because they tended to be present when people reported themselves to be happy.

A further point to the validity of subjective well-being scales like the Cantril Ladder is the ability of live evaluations in large populations to predict subsequent events, such as suicide frequencies, providing strong evidence that life evaluations are important to affect behavior. The fact that these measures have been shown to be predictive of sickness and death only strengthens the need for collecting such measures within regular health care delivery.

A theorized happiness "set point" has been discussed in the literature, which challenges life evaluation measures by stating that each individual has their own set point based on stable personality traits, consistently returning to that baseline after any life changes. Yet if this were the case, we would not see such large and long-standing international differences in life evaluation; for example, the top ten countries measured by the World Happiness Report (Helliwell et al., 2012) are twice as high as the bottom ten countries, and these differences are largely explained by measured differences in life circumstances. Furthermore, data from a series of Canadian General Social Surveys spanning almost 25 years reveals that francophone 
residents of Quebec have seen (since Quebec's Quiet Revolution) steady growth in life satisfaction compared to similar samples of other Canadian province residents (BarringtonLeigh, C.P., 2011). Life satisfaction measures can capture more than temporary departures from personality-driven set points, and social changes can cause sustained trends in well-being far beyond those explicable by conventional economic measures.

For economists and policy-makers alike, the role of income on well-being is of continuous interest as there has been the grand assumption that higher incomes translates directly into an increase in an individual's satisfaction. However, recent studies comparing sub-country populations in low and high-income countries have found only a small effect of income on life satisfaction, relative to other life circumstances (Helliwell, 2003; Blanchflower and Oswald, 2004; Deaton, 2008).

In short, a household's income is often associated with happiness (Blanchflower et al. 2004), especially within highly developed countries such as the U.S. or UK, however other factors may be more influential to life satisfaction (the evaluative side of well-being): community trust, employment, mental and physical health, and the quality of governance and rule of law (Helliwell et al., 2012). Raising incomes can raise happiness, most effectively in low-income populations, but fostering these other community-oriented and health-focused factors can do even more, notably in high-income countries that have a low marginal utility of income. 
The relationship between age and evaluations of happiness is a frequently researched aspect within well-being. Although most people would expect that happiness steadily declines with age, as many physical and mental faculties weaken, study results have yet to verify any universal trend. In UK and US populations, there is a clear trend in younger respondents reporting higher life satisfaction than older individuals, but this is not a well-defined development (Blanchflower, D.G., Oswald, A., 2004). Meanwhile, life-evaluation surveys from both LMIC and high income countries have found a reoccurring U-shaped pattern beginning in adolescence (Hayo, B., \& Seifert, W., 2003): satisfaction consistently declining, reaching a minimum in middle-age (between 40 and 50), and then rising again. This U-shape is more pronounced when controlling for income, marital status, health and employment status, reinforcing the fact that it is not only higher income or greater stability that explains the happiness increase after the mid-life point.

Many studies have shown a strong correlation to exist between marital status of men and women and perceived well-being, notably Helliwell (2003) who found those reported as married were more likely to report being happiest on a spectrum scale, or report higher life satisfaction, followed by the classification group 'living as married'. Moreover, the single greatest depressant of reported happiness was the variable 'separated', closely followed by 'widowed', reinforcing the fact that marital status has had a large effect on US and UK populations in the last quarter century (Blanchflower et al. 2004).

The total reported years of education often correlates positively with life satisfaction. However 
this correlation can vary from country to country as well as between cultures. Some studies have found that effects of different levels of education on well-being are small and insignificant (Helliwell et al. 2003), though the studies that found weak correlations of this nature typically collected data based on ages at which full-time education was finished, a limitation primarily due to survey design. Although the traditional economist perspective disagrees, educational attainment can act independently on well-being, not only as a proxy for income earnings. An analysis from Blanchflower et al. (2004) reveals that it is not earnings directly which has the strong observed effect on well-being, but rather education represents its own independent effect on well-being, apart from income.

\subsection{Limitations}

The cross-sectional nature of this study poses a limitation, as we cannot ascertain whether life satisfaction rates will change with food insecurity status over time. Additionally due to the study using a cross-sectoral approach, the current study is able to identify association, but not causal relationships. Another limiting factor of this study is the gender categorization, institutionalized by Gallup's methodology, which provides survey respondents with only two options (male or female) for their identifying gender. Further, due to the nature of the GWP methodology, it is not possible to ascertain what household role the respondent had, or if the respondent was the most knowledgeable of food issues for the household. The sample size of 1,000 respondents per country (excluding those larger population countries such as India or Russia) is a limitation that can hinder conclusions which can be reached about a particular 
country, as well as a lack of representation of minority populations or indigenous populations.

\subsection{Conclusions}

This study highlights the importance of reliable, individual-level food insecurity and well-being data collection, and confirms previous literature measuring gender disparities in food insecurity, though the current study identifies a slightly higher risk of food insecurity for women than men across 120 countries. This enriches the current body of knowledge by showing that this disparity in food security trend does in fact include those higher income countries, as well as low-income countries.

These findings further reveal that men are significantly more likely to report low life satisfaction than their female counterparts. While it is generally understood that women rank their life satisfaction higher on average than men, the added adjustment of food insecurity does not sway this trend on a global scale. The food insecure men were found to be the most vulnerable group to perceiving low life satisfaction, compared to food secure women. This finding is of paramount interest to food security and well-being researchers alike, as it is the first time a global comparison has been made to show gender differences in life satisfaction, when controlling for food insecurity at the individual level. This evidence supports a new area of research, confirming significantly different perceptions of life satisfaction between men and women who experience the same food insecurity status. 
It has been demonstrated throughout this study that in order to measure the progress of societies, we need to develop and uniformly administer reliable indicators that extend beyond the traditional measures for well-being and food security. The present study provides evidence of using experience-based food insecurity indicators to yield nuanced and reliable information for international and national-level policymaking. But for such policies to effect change in a sustainable manner, continuous data are needed specifically measuring the gender roles where food insecurity exists, and what restraints men and women face which are unique to their food insecurity severity and locale.

A key strength of this study was the large and diverse sample provided by the 2014 GWP, which allowed the relationship between food security and life satisfaction to be explored in a geographically and culturally diverse sample of individuals.

\subsection{Tables}

Table 4.1 Characteristics of the sample (weighted)

\begin{tabular}{l|c|c} 
Categorical Variables & \% & 95\% Cl \\
\hline Food Security & 52.3 & $52.0-52.6$ \\
Food Secure & 47.7 & $47.4-48.0$ \\
Food Insecure & & \\
\hline Life Satisfaction & 32.4 & $32.1-32.7$ \\
"Worse off" & 67.6 & $67.3-67.9$ \\
"Better off" & & $48.6-49.2$ \\
\hline Gender & 48.9 & $50.8-51.4$ \\
Men & 51.1 & \\
Women & & $39.5-40.1$
\end{tabular}




\begin{tabular}{l|c|c} 
Some Secondary & 47.7 & $47.4-48.0$ \\
Completed Tertiary & 12.5 & $12.3-12.7$ \\
\hline Marital Status & & \\
Single & 31.9 & $31.6-32.2$ \\
Married/ Partner & 57.3 & $57.0-57.6$ \\
Separated/ Divorced & 4.9 & $4.8-5.0$ \\
Widowed & 5.8 & $5.7-6.0$ \\
\hline Continuous Variables & Estimate Mean & $95 \% \mathrm{Cl}$ \\
\hline Age & 39.4 & $39.3-39.5$ \\
\hline Income & $6,734.3$ & $6,634.7-6,833.9$
\end{tabular}

Table 4.2 Bivariate analysis of sample characteristics by food insecurity status

\begin{tabular}{|c|c|c|c|}
\hline Characteristics & $\begin{array}{l}\text { Food secure }(n= \\
\qquad 74,001)\end{array}$ & $\begin{array}{l}\text { Food insecure } \\
\qquad(n=65,087)\end{array}$ & P Value \\
\hline \multicolumn{4}{|l|}{ Life satisfaction } \\
\hline Better off (score 5-10) & 83.1 & 50.1 & 0.00 \\
\hline Worse off (score $0-4$ ) & 16.9 & 49.9 & \\
\hline \multicolumn{4}{|l|}{ Education level } \\
\hline Elementary or less & 26.6 & 54.3 & \\
\hline Some secondary & 54.9 & 39.7 & 0.00 \\
\hline Completed tertiary & 18.5 & 6.0 & \\
\hline \multicolumn{4}{|l|}{ Marital status } \\
\hline Single & 32.5 & 31.3 & \\
\hline Married/ Partnered & 57.9 & 56.8 & 0.00 \\
\hline Widowed & 5.2 & 6.6 & \\
\hline Separated/ Divorced & 4.5 & 5.4 & \\
\hline Continuous variables & Food Secure & Food Insecure & P Value \\
\hline Income & $10,213.4$ & $2,901.4$ & 0.00 \\
\hline Age & 40.8 & 37.9 & 0.00 \\
\hline
\end{tabular}

${ }^{*}$ Categorical variables expressed in weighted \%; Continuous variables expressed in weighted mean; $p<0.05 ; p$ values correspond to differences between food security status 
Table 4.3 Bivariate analysis of sample characteristics by gender

\begin{tabular}{l|c|c|c} 
Characteristics & Men & Women & P Value \\
\hline Food security status & 53.9 & 50.8 & 0.00 \\
Food secure & 46.1 & 49.2 & \\
Food insecure & & & \\
\hline Life satisfaction & 67.1 & 68.6 & 0.00 \\
Better off (score 5-10) & 32.9 & 31.4 & \\
Worse off (score 0-4) & & & \\
\hline Education level & 37.1 & 42.4 & 0.00 \\
Elementary or less & 49.9 & 45.6 & \\
Some secondary & 13.0 & 12.0 & \\
Completed tertiary & & & \\
\hline Marital status & 36.7 & 27.3 & 0.00 \\
Single & 57.0 & 57.7 & 0.00 \\
Married/ Partnered & 2.6 & 8.9 & \\
Widowed & 3.7 & 6.1 & \\
Separated/ Divorced & Men & Women & \\
\hline Continuous Variables & 757.2 & 6.329 .5 & \\
\hline Per capita income & & & \\
\hline Age & & & \\
values correspond to differences between genders & & \\
\hline
\end{tabular}

Table 4.4 Bivariate analysis of sample characteristics by life satisfaction category

\begin{tabular}{l|c|c|c} 
Characteristics & Better off & Worse off & P Value \\
\hline Education level & 29.8 & 58.5 & \\
Elementary or less & 53.8 & 36.4 & 0.00 \\
Some secondary & 16.4 & 5.1 & \\
Completed tertiary & & & \\
\hline Marital status & 32.9 & 29.8 & 0.00 \\
Single & 57.5 & 57.1 & \\
Married/ Partnered & &
\end{tabular}




\begin{tabular}{l|c|c|c} 
Widowed & 4.9 & 7.6 & \\
Separated/ Divorced & 4.7 & 5.4 & \\
\hline Continuous Variables & Better off & Worse off & P Value \\
\hline Per capita income & 8,783 & 2,694 & 0.00 \\
\hline Age & 39.5 & 39.4 & NS
\end{tabular}

Table 4.5 Logistic regressions OR for food insecurity by gender

\begin{tabular}{l|c|c} 
Reference category: men & OR & $95 \% \mathrm{Cl}$ \\
\hline Women (unadjusted OR) & 1.135 & $1.107-1.163$ \\
\hline Women (adjusted OR)* & 1.044 & $1.016-1.074$
\end{tabular}

*Adjusted by Age, Marital Status, Per Capita Income, Household size Education Level and Country of Residence; performed Wald test; $p<0.05$

Table 4.6 Logistic regression, unadjusted and adjusted OR for life satisfaction

\begin{tabular}{l|c|c|c|c}
\multicolumn{2}{l|}{ Reference category: food secure women } & Odds Ratio & $95 \% \mathrm{Cl}$ & P Value \\
\hline Unadjusted OR & 5.649 & 5.412 & 5.896 \\
\hline \multicolumn{1}{l|}{ Food insecure men } & 5.065 & 4.860 & 5.279 \\
\hline Food insecure women & 1.177 & 1.124 & 1.232 \\
\hline Food secure men & & & \\
\hline \hline Adjusted OR* & 3.890 & 3.715 & 4.074 \\
\hline Food insecure men & 3.310 & 3.164 & 3.462 \\
\hline Food insecure women & 1.241 & 1.183 & 1.301 \\
\hline Food secure men
\end{tabular}

*Adjusted for Age, Marital Status, Per Capita Income, Household size Education Level and Country of Residence; performed Wald test; $\mathrm{p}<0.05$ 


\section{Chapter 5: Final Conclusions}

This study highlights the importance of reliable, individual-level food insecurity and well-being data collection, and confirms previous literature measuring gender disparities in food insecurity, though the current study identifies a slightly higher risk of food insecurity for women than men across 120 countries. This enriches the current body of knowledge by showing that this disparity in food security trend does in fact include those higher income countries, as well as low-income countries. Further, because the $95 \%$ confidence interval does not include 1.00, this result is statistically significant, especially when considering the robust size of our sample.

These findings further reveal that men are significantly more likely to report low life satisfaction than their female counterparts. While it is generally understood that women rank their life satisfaction higher on average than men, the added adjustment of food insecurity does not sway this trend on a global scale. The food insecure men were found to be the most vulnerable group to perceiving low life satisfaction, compared to food secure women. This finding is of paramount interest to food security and well-being researchers alike, as it is the first time a global comparison has been made to show gender differences in life satisfaction, when controlling for food insecurity at the individual level. This evidence supports a new area of research, confirming significantly different perceptions of life satisfaction between men and women who experience the same food insecurity status.

It has been demonstrated throughout this study that in order to measure the progress of societies, we need to develop and uniformly administer reliable indicators that extend beyond 
the traditional measures for well-being and food security. The present study provides evidence of using experience-based food insecurity indicators to yield nuanced and reliable information for international and national-level policymaking. But for such policies to effect change in a sustainable manner, continuous data are needed specifically measuring the gender roles where food insecurity exists, and what restraints men and women face which are unique to their food insecurity severity and locale.

A key strength of this study was the large and diverse sample provided by the 2014 GWP, which allowed the relationship between food security and life satisfaction to be explored in a geographically and culturally diverse sample of individuals.

This study supports the use of indicators like the FIES in the context of tracking global food insecurity and measuring progress of international commitments, such as the Scaling Up Nutrition (SUN) movement and the Sustainable Development Goals (SDGs). It is demonstrated in the present study that using experience-based food insecurity indicators can yield nuanced and reliable information for international and national-level policymaking.

More reliable and consistent data are needed which can specifically measure the gender roles where food insecurity exists, and what restraints men and women face which are unique to their food insecurity severity and locale. Such gender roles, especially those relating to agricultural productivity and access to resources, have continued to change over time, creating 
new opportunities for both genders to aid their food security situation and larger food environment. Policy must be founded on such knowledge and supporting data.

In addition, governments should begin the systematic measurement of happiness itself, in both its affective and evaluative dimensions. Beyond the inherent interest of mapping the relativity of satisfaction, there are policy-related reasons for monitoring subjective measures of wellbeing. Of critical importance, many public policies have effects on well-being that flow through productivity and income measures, as well as through other channels. Conventional economic analysis can recognize the generally positive affect through increased GNP or per capita earnings, but unless we invest in indicators that can track the offsetting influences through subjective well-being, the net effects of the policy will elude us. Moving forward, policy-makers must balance the pursuit of rapid economic growth with other (more sustainable) sources of happiness, such as life evaluation, which will continue to be affected by food insecurity. This movement applies to countries at every level of development.

Future research should explore why life satisfaction is reported differently by gender (all things considered), what the consequences are then for these food insecure populations, and what implications exist for policies that aim to improve food crises. 


\section{References}

Asian Development Bank. (2013). Gender equality and food security-women's empowerment as a tool against hunger. Mandaluyong City, Philippines: Asian Development Bank, FAO.

Ballard, T.J., Kepple, A.W. \& Cafiero, C. (2013). The food insecurity experience scale: developing a global standard for monitoring hunger worldwide. Technical Paper. Rome, FAO. (available at http://www.fao.org/economic/ess/ess-fs/voices/en/).

Ballard, T.J., Coates, J., Swindale, A. \& Deitchler, M. (2011). Household hunger scale: indicator definition and measurement guide. Washington, DC: FANTA-2 Bridge, FHI 360.

Bardales, D. \& Arenas, P. (2014). The World We Want - A Future For All. Latin America and Caribbean Movement for Children, 2015. A publication of the Global Movement for Children of Latin America and Caribbean - MMI-LAC.

Barrington-Leigh, C.P. (2011). The Québec convergence and Canadian life satisfaction 1985 2008. Retrieved from http://wellbeing.ihsp.mcgill.ca/publications/BarringtonLeighDRAFTQuebec.pdf

Bernal, J., Frongillo, E.A., Salgado, T., Candela, Y., Herrera, H. \& Rivera, J.A. (2012). Design and validation of experienced-based tools that measure food insecurity and hunger in vulnerable populations of children and seniors in a developing country. Presentation at the FAO International Scientific Symposium, Rome, 18 January. (available at http://www.foodsec.org/fileadmin/user_upload/eufaofsi4dm/docs/German_1400_JBernal.pdf).

Blanchflower, David G., and Andrew Oswald. (2004). "Well-Being over Time in Britain and the USA." Journal of Public Economics, 88(7-8): 1359-86.

Blanchflower, D. G. (2008). International evidence on well-being. NBER Working Paper 14318.

Brown, L., Deshpande, C., Hill, C., Lambrou, Y., Laudazi, M., \& Ragasa, C. (2008). Module 1: Gender and Food Security. Project funded by the United Nations Foundation. Implemented by FAO.

Brunelli, C., Viviani, S. (2014). Exploring gender disparities with the FAO Food Insecurity Experience Scale. Statistics Division, Food and Agriculture Organization of the United Nations (FAO), Italy. Presented at the "2014 Global Forum on Gender Statistics", Aguascalientes, Mexico, 3-5 November 2014.

Cafiero, C., Melgar-Quinonez, H. R., Ballard, T., Kepple, A. (2014). Validity and reliability of food security measures. Ann. N.Y. Acad. Sci. ISSN 0077-8923 
Coates, J., Wilde, P.E., Webb, B., Rogers, L. \& Houser, R.F. (2006). Comparison of a qualitative and a quantitative approach to developing a household food insecurity scale for Bangladesh. Journal of Nutrition, 136: 1420S-1430S

Coates, J., Swindale, A., \& Bilinsky, P. (2007). Household Food Insecurity Access Scale (HFIAS) for measurement of household food access: indicator guide (v. 3). Food and Nutrition Technical Assistance Project, Academy.

Cantril, H. (1977). Pattern of Human Concerns Data, 1957-1963, Codebook. Inter-university Consortium for Political and Social Research (ICPSR).

Deaton, A. (2008). Income, Health, and Well-Being around the world: Evidence from the Gallup World Poll. Journal of Economic Perspectives. Volume 22, Number 2. Spring 2008. Pages 53-72.

Deaton, A. (2010), "Price Indexes, Inequality and the Measurement of World Poverty", American Economic Review 2010, 100:1.

http://www.academia.edu/2687788/Price_indexes_inequality_and_the_measurement_ of_world_poverty.

Dolan, P. and White, M.P. (2007). "How can measures of subjective well-being be used to inform policy?" Perspectives on Psychological Science, Vol. 2(1), pp. 71-85.

Doss C. (2011). If women hold up half the sky, how much of the world's food do they produce? ESA Working Paper No. 11-04. Rome: Agricultural Development Economic Division Food and Agricultural Organisation of the United Nations. Available from http://www.fao.org/docrep/013/am309e/am309e00.pdf

Easterlin, R.A. (1974). “Does Economic Growth Improve the Human Lot? Some Empirical Evidence." In Nations and Households in Economic Growth: Essays in Honor of Moses Abramovitz, ed. Paul A. David and Melvin W. Reder, 89-125. New York: Academic Press.

ESS. (2015). European Social Survey. Questionnaire: Core Module. Accessed on 10 April 2015 at http://www.europeansocialsurvey.org/methodology/questionnaire/

EVS. (2014). European Values Study: Methods and sample- Survey 2008. Last updated 2014. Accessed at http://www.europeanvaluesstudy.eu/frmShowpage?v_page_id=1680373125305663

FIVIMS. (2002). FIVISM: an inter-agency initiative to promote information and mapping systems on food insecurity and vulnerability. Summary of Proceedings: Measurement and Assessment of Food Deprivation and Undernutrition. International Scientific Symposium, Rome, 26-28 June 2002. 
Food and Agriculture Organization of the United Nations. (1996). FAO: Rome declaration on world food security. World Food Summit. Food and Agriculture Organization of the United Nations.

Food and Agriculture Organization of the United Nations. (1997). FAO Focus on Women and Food Security. FAO. http://www.fao.org/focus/e/women/sustin-e.htm

Food and Agriculture Organization of the United Nations. (2006). Food Security Policy Brief. Food and Agriculture Organization of the United Nations.

Food and Agricultural Organization of the United Nations. (2011). International C. Combating Micronutrient Deficiencies: Food-based Approaches. Rome: FAO, 2011.

Food and Agriculture Organization of the United Nations. (2012). State of Food Insecurity. Rome (available at http://www.fao.org/docrep/016/i3027e/i3027e.pdf).

FAO, IFAD and WFP. (2013). The State of Food Insecurity in the World 2013. The multiple dimensions of food security. Rome, FAO.

Food and Agriculture Organization of the United Nations (2015). FAOSTAT. Accessed at http://faostat.fao.org/ on 8 April 2015.

FAO, IFAD and WFP. (2015). The State of Food Insecurity in the World 2015. Meeting the 2015 international hunger targets: taking stock of uneven progress. Rome, FAO.

Fram, M.S., Frongillo, E.A., Jones, S.J., Williams, R.C., Burke, M.P., DeLoach, K.P \& Blake, C.E. (2011). Children are aware of food insecurity and take responsibility for managing food resources. Journal of Nutrition, 141(6): 1114-9.

Frongillo, E.A. (2003). Understanding obesity and program participation in the context of poverty and food insecurity. Journal of Nutrition,133: 2225-2231.

Gallup. (2009). World Poll Methodology. Technical Report. Washington, DC.

Gallup. (2015). "How does the Gallup World Poll Work? Measures the Attitude and Behaviors of the World's Residents" Retrieved January 2015 at http://www.gallup.com/178667/gallup-world-poll-work.aspx

Gebrehiwot, T., \& Van der Veen, A. (2014). Coping with food insecurity on a micro-scale; evidence from Ethiopian rural households. Ecology of Food and Nutrition, 53:2, 214-240.

Gross National Happiness. (2015). Bhutan GNH Index: GNH: Concept. Accessed on 10 April 2015 at http://www.grossnationalhappiness.com/articles/ 
Hamelin, A.M., Beaudry, M., Habicht, J.P. (2002). Characterization of household food insecurity in Québec: food and feelings. Soc Sci Med., 54:119-32

Hayo, B., \& Seifert, W. (2003). Subjective economic well-being in Eastern Europe. Journal of Economic Psychology, 24(3), 329-348.

Helliwell, J.F., R. Layard and J. Sachs (eds.) (2012), World Happiness Report, Earth Institute, New York, Columbia University, available online at: www.earthinstitute.columbia.edu/sitefiles/file/Sachs\%20Writing/2012/World\%20Happi ness\%20Report.pdf.

Helliwell, John F. (2003). "How's Life? Combining Individual and National Variables to Explain Subjective Well-Being." Economic Modeling, 20(2): 331-60.

Holmqvist, G. and L. Natali (2014). Exploring the Late Impact of the Great Recession Using Gallup World Poll Data, Innocenti Working Paper No.2014-14, UNICEF Office of Research, Florence, Italy.

International Food Policy Research Institute. (2014). Global Nutrition Report 2014: Actions and Accountability to Accelerate the World's Progress on Nutrition. Washington, DC.

Kahneman, D., Fredrickston, B.L., Schreiber, C.A., Redelmeier, D.A. (1993) "When More Pain is Preferred to Less: Adding a Better Ending", Research Report. American Psychological Society, Vol. 4, No. 6, pages 401-405. November 1993.

Kahneman, D., Deaton, A. (2010). High income improves evaluation of life but not emotional well-being. Proceedings of the National Academy of Science (PNAS), 4 August 2010.

Larsen, R.J., Diener, E., Emmons, R.A. (1985). An Evaluation of Subjective Well-being Measures. Dept. of Psychology, Purdue University. Social Indicators Research 17 (1985) 1-17. 0303 $8300 / 85.10$

Larsen, R.J., Diener, E., \& Emmons, R.A. (1985). An evaluation of subjective wellbeing measures. Social Indicators Research, 17, 1-17.

Lemke, S., Vorster, H.H., Jansen van Rensburg, N.S., \& Ziche, J. (2003). Empowered women, social networks and the contribution of qualitative research: broadening our understanding of underlying causes for food and nutrition insecurity. Public Health Nutrition, 6, 759e764.

Layard, Richard. (2005). Happiness: Lessons from a New Science. New York: Penguin Press.

Melgar-Quiñonez, H, \& Hackett, M. (2008). Measuring household food security: the global 
experience. Revista de Nutrição, 21:27-38.

Monteiro, C.A., Conde, W.L. \& Popkin, B.M. (2004). The burden of disease from undernutrition and overnutrition in countries undergoing the nutrition transition: a view from Brazil. American Journal of Public Health, (94):433-4.

Moreno-Black, G., \& Guerron-Montero, C. (2005). Speaking of hunger and coping with food insecurity: experience in the Afroecuadorian Highlands. Ecology of Food \& Nutrition, 44, $391 \mathrm{e} 420$.

Nanama, S., Frongillo, E.A. (2012). Altered social cohesion and adverse psychological experiences with chronic food insecurity in the non-market economy and complex households of Burkina Faso. Social Science \& Medicine. Vol. 74, issue 3, pages 444-451.

National Research Council. (2006). Food insecurity and hunger in the United States: an assessment of the measure. Panel to review the U.S. department of agriculture's measurement of food insecurity and hunger. In G. S. Wunderlich, \& J. L. Norwood (Eds.), Committee on national statistics, division of behavioral and social sciences and education. Washington, DC: The National Academies Press.

Nolen-Hoeksema, S., \& Rusting, C. L. (1999). Gender differences in well-being. In D. Kahneman, E. Diener, \& N. Schwarz (Eds.), Well-Being: The Foundations of Hedonic Psychology. Russell Sage Foundation, New York.

Nord, M., 2011. Intra-household differences in food security among adults in NHANES. Paper presented at the Third North American Congress on Epidemiology, Montreal, Quebec, Canada, June 2010

Nord, M. (2014). Introduction to Item Response Theory applied to Food Security Measurement: Basic Concepts, Parameters, and Statistics. Technical Paper, FAO, Rome. (available at http://www.fao.org/economic/ess/ess-fs/voices/en)

OECD. (2013). OECD Guidelines on Measuring Subjective Well-being, OECD Publishing. http://dx.doi.org/10.1787/9789264191655-en

OECD. (2014). Better Life Index: http://www.oecdbetterlifeindex.org/about/better-life initiative/

Office of the UN High Commissioner for Human Rights. (2010). The Right to Adequate Food. Fact Sheet No. 34. Printed at United Nations, Geneva. ISSN 1014-5567.

ONS. (2011). Initial investigation into Subjective Wellbeing from the Opinions Survey, Office for National Statistics. 
Pérez-Escamilla, R., Melgar-Quiñonez, H., Nord, M., Alvarez Uribe, M.C., Segall-Correa, A.M. (2007). Escala Latinoamericana y Caribeña de Seguridad Alimentaria (ELCSA) [Latinamerican and Caribbean Food Security Scale]. Perspectivas en Nutrición Humana, Colombia (supplement):117-134

Perez-Escamilla, R. \& Segall-Correa, A.M. (2008). Food insecurity measurement and indicators. Rev. Nutr. [online]. 2008, vol.21, suppl., pp. 15s-26s. ISSN 1415-5273.

Piaseu, N., Belza, B., \& Shell-Duncan, B. (2004). Less money less food: voices from women in urban poor families in Thailand. Health Care for Women International, 25, 604e619.

Radimer, K., C.M. Olson \& C.C. Campbell. (1990). Development of indicators to assess hunger. J.Nutr. 120(Suppl.): 1544S-1548S.

Radimer, K.L., Olson, C.M., Greene, J.C., Campbell, C.C. \& Habicht, J.P. (1992). Understanding hunger and developing indicators to assess it in women and children. Journal of Nutrition Education (24) Suppl:36-45

Rio+20 United Nations Conference on Sustainable Development. (2012). The Future We Want Zero draft of the outcome document.

Samson, S.A., (1978). "Hadley Cantril: The Pattern of Human Concerns Study Guide". Faculty Publications and Presentations. Paper 246. http://digitalcommons.liberty.edu/gov_fac_pubs/246

Sen, A. (1981). Poverty and Famines: An Essay on Entitlement and Deprivation. Oxford: Clarendon Press

Swindale, A. \& Bilinsky, P. (2006). Development of a universally applicable household food insecurity measurement tool: process, current status, and outstanding issues. Journal of Nutrition.136: 1449S-1452S.

United Nations Economic and Social Council [ECOSOC]. (2007). Paragraph 14, p. 6.

United Nations Human Rights. (1976). International Covenant on Economic, Social and Cultural Rights. Entry into force 3 Jan. 1976. Accessed at http://www.ohchr.org/EN/Professionallnterest/Pages/CESCR.aspx on 10 April 2015.

United Nations Millennium Declaration. (2000). Resolution adopted by the General Assembly, 55/2 United Nations Millennium Declaration. I. Values and Principles, 6. Freedom. Accessed at http://www.un.org/millennium/declaration/ares552e.htm on 10 April 2015.

USDA. (2014). United States Department of Agriculture; Economic Research Service. Survey Tools. Last Updated: 3 September 2014. Accessed at 
http://www.ers.usda.gov/topics/food-nutrition-assistance/food-security-in-theus/survey-tools.aspx\#household on 10 April 2015.

Veenhoven Ruut. (1991). "Is Happiness Relative?" Social Indicators Research, 24(1), 1-34.

Voices of the Hungry. (2015). The Food Insecurity Experience Scale: an experience-based food insecurity measure. Accessed July 2015. Retrieved at http://www.fao.org/economic/ess/ess-fs/voices/en/

Von Grebmer, K., Saltzman, A., Birol, E., Wiesmann, D., Prasai, N., Yin, S., Yohannes, Y., Menon, P., Thompson, J., Sonntag, A. (2014). 2014 Global Hunger Index: The Challenge of Hidden Hunger. Bonn, Washington, D.C., and Dublin: Welthungerhilfe, International Food Policy Research Institute, and Concern Worldwide.

Webb P, Coates J, Frongillo EA, Rogers BL, Swindale A, Bilinsky P. (2006). Measuring household food insecurity: why it's so important and yet so difficult to do. Journal of Nutrition, 136(5):1404S-1408S

White, S., \& Jha, S. (2014). Social Protection and Wellbeing: Food Security in Adivasi communities, Chhattisgarh, India. Wellbeing and Poverty Pathways Briefing No. 3. An ESRC/ DFID Research Project, University of Bath.

Wolfe, W.S., Olson, C.M., Kendall, A. \& Frongillo, E.A. (1996). Understanding food insecurity in the elderly: a conceptual framework. Journal of Nutrition Education, 28(2): 92-100.

World Bank. (2014). Financial Inclusion Index: http://econ.worldbank.org/WBSITE/EXTERNAL/EXTDEC/EXTRESEARCH/EXTPROGRAMS/ EXTFINRES/EXTGLOBALFIN/0,,contentMDK:23147627 pagePK:64168176 piPK:6416814 0 theSitePK:8519639,00.html

World Food Programme. (2009). Emergency Food Security Assessments (EFSAs) Technical guidance sheet, No. 5. Distinguishing between chronic and transitory food insecurity in emergency food security assessments.

World Food Programme. (2011). 11 Myths About Global Hunger. World Food Programme, accessed at https://www.wfp.org/stories/11-myths-about-global-hunger on 10 April 2015. Published 21 October 2011.

WVS. (2015). Data and Documentation. World Values Survey Accessed on 10 April 2015 at http://www.worldvaluessurvey.org/WVSContents.jsp

Zakari, S., Ying, L., \& Song, B. (2014). Factors influencing household food security in West Africa: The case of southern Niger. Sustainability, 6(3), 1191-1202. 


\section{Appendices}

\section{Appendix A.}

\section{GLOBAL FOOD INSECURITY EXPERIENCE SCALE used in 2014 Gallup World Poll}

(Recall period 12 months, measured at individual level, score based on first 8 questions while final 2 child questions used for context analysis.)

Now I would like to ask you some questions about your food consumption in the last 12 months.

During the last 12 MONTHS, was there a time when:

Q1. You were worried you would run out of food because of a lack of money or other resources?

Q2. You were unable to eat healthy and nutritious food because of a lack of money or other resources?

Q3. You ate only a few kinds of foods because of a lack of money or other resources?

Q4. You had to skip a meal because there was not enough money or other resources to get food?

Q5. You ate less than you thought you should because of a lack of money or other resources?

Q6. Your household ran out of food because of a lack of money or other resources?

Q7. You were hungry but did not eat because there was not enough money or other resources for food?

Q8. You went without eating for a whole day because of a lack of money or other resources?

$\begin{array}{ll}0 & \text { No } \\ 1 & \text { Yes }\end{array}$

98 Doa't Know

99 Refused

$\begin{array}{ll}0 & \text { No } \\ 1 & \text { Yes }\end{array}$

98 Doa't Know 99 Refused

0 No

98 Don't Know 99 Refused

0 No

1 Yes

98 Don't Know 99 Refused

0 No

98 Doa't Know 99 Refused

0 No

1 Yes

98 Don't Know

99 Refused

0 No

1 Yes

98 Doa't Know

99 Refused

0
1

1 Yes

88 Doa't Know

99 Refused 